\title{
High-resolution digital mapping of soil organic carbon in permafrost terrain using machine learning: a case study in a sub-Arctic peatland environment
}

\author{
Matthias B. Siewert ${ }^{1,2}$ \\ ${ }^{1}$ Department of Physical Geography, Stockholm University, Stockholm, 106 91, Sweden \\ ${ }^{2}$ Department of Ecology and Environmental Science, Umeå University, Umeå, 901 87, Sweden
}

Correspondence: Matthias B. Siewert (matthias.siewert@umu.se)

Received: 25 July 2017 - Discussion started: 4 August 2017

Revised: 11 January 2018 - Accepted: 13 February 2018 - Published: 21 March 2018

\begin{abstract}
Soil organic carbon (SOC) stored in northern peatlands and permafrost-affected soils are key components in the global carbon cycle. This article quantifies SOC stocks in a sub-Arctic mountainous peatland environment in the discontinuous permafrost zone in Abisko, northern Sweden. Four machine-learning techniques are evaluated for SOC quantification: multiple linear regression, artificial neural networks, support vector machine and random forest. The random forest model performed best and was used to predict SOC for several depth increments at a spatial resolution of $1 \mathrm{~m}(1 \times 1 \mathrm{~m})$. A high-resolution $(1 \mathrm{~m})$ land cover classification generated for this study is the most relevant predictive variable. The landscape mean SOC storage $(0-150 \mathrm{~cm})$ is estimated to be $8.3 \pm 8.0 \mathrm{~kg} \mathrm{C} \mathrm{m}^{-2}$ and the SOC stored in the top meter $(0-100 \mathrm{~cm})$ to be $7.7 \pm 6.2 \mathrm{~kg} \mathrm{C} \mathrm{m}^{-2}$. The predictive modeling highlights the relative importance of wetland areas and in particular peat plateaus for the landscape's SOC storage. The total SOC was also predicted at reduced spatial resolutions of 2,10,30,100, 250 and $1000 \mathrm{~m}$ and shows a significant drop in land cover class detail and a tendency to underestimate the SOC at resolutions $>30 \mathrm{~m}$. This is associated with the occurrence of many small-scale wetlands forming local hot-spots of SOC storage that are omitted at coarse resolutions. Sharp transitions in SOC storage associated with land cover and permafrost distribution are the most challenging methodological aspect. However, in this study, at local, regional and circum-Arctic scales, the main factor limiting robust SOC mapping efforts is the scarcity of soil pedon data from across the entire environmental space. For the Abisko region, past SOC and permafrost dynamics indicate that most of the SOC is barely 2000 years old and very dynamic. Fu-
\end{abstract}

ture research needs to investigate the geomorphic response of permafrost degradation and the fate of SOC across all landscape compartments in post-permafrost landscapes.

\section{Introduction}

Northern high latitudes are among the regions most affected by increasing temperatures and climate change (IPCC, 2013). Large amounts of soil organic carbon (SOC) and the abundance of wetlands as a substantial source of methane $\left(\mathrm{CH}_{4}\right)$, are factors that make this region a key component in the global carbon (C) cycle (McGuire et al., 2009). Frozen conditions, cold temperatures and waterlogging are characteristics of wetlands, peatlands and permafrost-affected soils that reduce decomposition rates of SOC (Davidson and Janssens, 2006; Ping et al., 2015). This has led to the accumulation of large stocks of SOC in high-latitude ecosystems (Tarnocai et al., 2009). SOC stocks in the circumpolar permafrost region are estimated to be $\sim 1300 \mathrm{Pg}$, including soils to a depth of $3 \mathrm{~m}$ and other unconsolidated deposits (Hugelius et al., 2014) . This corresponds to around half of the global SOC stocks (Köchy et al., 2015). A significant proportion of this SOC is stored in northern wetland and peatland areas (Gorham, 1991). However, warming temperatures and environmental changes caused by warming of soils and consequent permafrost degradation are projected to lead to a gradual and prolonged release of greenhouse gases in the future (Schuur et al., 2015). 
Circumpolar mapping efforts of SOC provide important input data for Earth system models. At the same time, highresolution mapping efforts are necessary to understand the substantial local-scale spatial and vertical variability of SOC in permafrost-affected soils (Siewert et al., 2015, 2016). Thematic maps are commonly used to map SOC from point measurements to a landscape scale in permafrost environments (Hugelius, 2012). This method is used in combination with soil maps to estimate SOC storage in the circumpolar permafrost region using the Northern Circumpolar Soil Carbon Database (NCSCD; Hugelius et al., 2014; Tarnocai et al., 2009). Land cover maps are also used at local to regional scales to estimate SOC values in numerous circumpolar environments (Fuchs et al., 2015; Hugelius et al., 2010, 2011; Hugelius and Kuhry, 2009; Palmtag et al., 2015; Siewert et al., 2015; Zubrzycki et al., 2013). While soil maps may better reflect soil properties and soil forming processes, a land cover classification (LCC) has the advantage that it can be readily generated from remote sensing data using the spatial resolution of the respective sensor. However, thematic mapping also represents a strong generalization, as equal soil properties are assumed for all areas covered by the same mapping class. Furthermore, for land cover maps there is an implicit assumption that land cover alone reflects belowground soil properties (Hugelius, 2012).

An alternative to thematic mapping is the use of predictive modeling methods. These can yield well-resolved pixelbased estimates of SOC. A comprehensive summary of these methods, commonly called digital soil mapping, is published by McBratney et al. (2003) and many examples are available, e.g., in Boettinger et al. (2010). However, in sub-Arctic and Arctic permafrost environments, the adoption of predictive modeling methods to map soil properties has been limited. Some examples include Bartsch et al. (2016), Baughman et al. (2015), Ding et al. (2016), Mishra and Riley (2012, 2014), and Pastick et al. (2014). The limited adoption has several reasons including the limited availability of environmental input data, the limited amount of soil pedon data (Mishra et al., 2013) and the large local-scale variability of permafrostaffected soils (Siewert et al., 2016). To cope with these limitations new mapping methods for permafrost environments are necessary to better constrain SOC stocks in the northern circumpolar permafrost region (Mishra et al., 2013). Such new methods include the use of machine learning in digital soil mapping (Hastie et al., 2009; Li et al., 2011). Machine learning in soil science covers a set of data-mining techniques that can recognize patterns in datasets and learn from these to predict quantitative soil variables. Many algorithms are available and robust prediction results are possible (Hastie et al., 2009; Li and Heap, 2008; Li et al., 2011). Testing these methods at different spatial resolutions can eventually improve local- and circumpolar-scale estimates of SOC.

Numerous ecosystem dynamics related to climate warming have been documented in sub-Arctic Sweden (Callaghan et al., 2013). These include the degradation of permafrost
(Åkerman and Johansson, 2008; Johansson et al., 2011), significant changes in surface structure in peat mires and changes in vegetation (Malmer et al., 2005). These changes can be associated with increases in landscape-scale $\mathrm{CH}_{4}$ emissions (Christensen et al., 2004). Analysis of presentday $\mathrm{C}$ fluxes indicate that losses from soil and over the hydrosphere currently offset $\mathrm{C}$ accumulation in peatlands and aboveground biomass making these ecosystems a $\mathrm{C}$ source (Lundin et al., 2016). To improve our understanding of these long-term permafrost-region $\mathrm{C}$ dynamics, highresolution maps of landscape distribution and partitioning of SOC are necessary. This should include the vertical partitioning of SOC and provide data that can be integrated into numerical models (Mishra et al., 2013; Schuur et al., 2015). Combined with a better temporal framework of past $\mathrm{C}$ dynamics, this will improve the projection of future climatic changes.

This study aims to compare four different machinelearning techniques for the prediction of SOC in a highlatitude permafrost and peatland environment. The mapping approach will be discussed with regard to its suitability to estimate SOC stocks in permafrost environments at local to circumpolar scales using different spatial resolutions. The results will provide high-resolution SOC storage data for a key sub-Arctic research site located in Abisko, northern Sweden. The study will give insights into the spatial and vertical partitioning of the SOC under different land covers and its association with different environmental variables. The temporal evolution of the SOC stocks over the Holocene will be interpreted from eight radiocarbon dates and the future development of SOC stocks and potential $\mathrm{C}$ release in high-latitude environments will be addressed.

\section{Study area}

The study area is a sub-Arctic mountain environment in the Abisko region near Stordalen, northernmost Sweden (Figs. 1 and 2). Environmental monitoring and research has been conducted for more than a century in this region and a particular interest has been the main peatland complex called Stordalen mire (Callaghan et al., 2013; Jonasson et al., 2012). The mapping extent covers two major peatland complexes, Stordalen and Storflaket, the surrounding birch forest and the adjacent alpine tundra zone. The altitude ranges from 342 to $932 \mathrm{~m}$ a.s.l. The total mapping area is $65 \mathrm{~km}^{2}$.

A mean annual air temperature of $0.5^{\circ} \mathrm{C}$ and a mean annual precipitation of $332 \mathrm{~mm}$ have been measured for the period 2002-2011 in Abisko (Callaghan et al., 2013). The study area is located in the zone of discontinuous permafrost (Brown et al., 1997). The onset of late Holocene permafrost aggradation in Stordalen was around 2650 cal BP (calibrated year) with a first phase that lasted until $2100 \mathrm{cal} \mathrm{BP}$ and a second phase after ca. 700 cal BP (Kokfelt et al., 2010). Today, the occurrence of permafrost at lower elevations is confined 


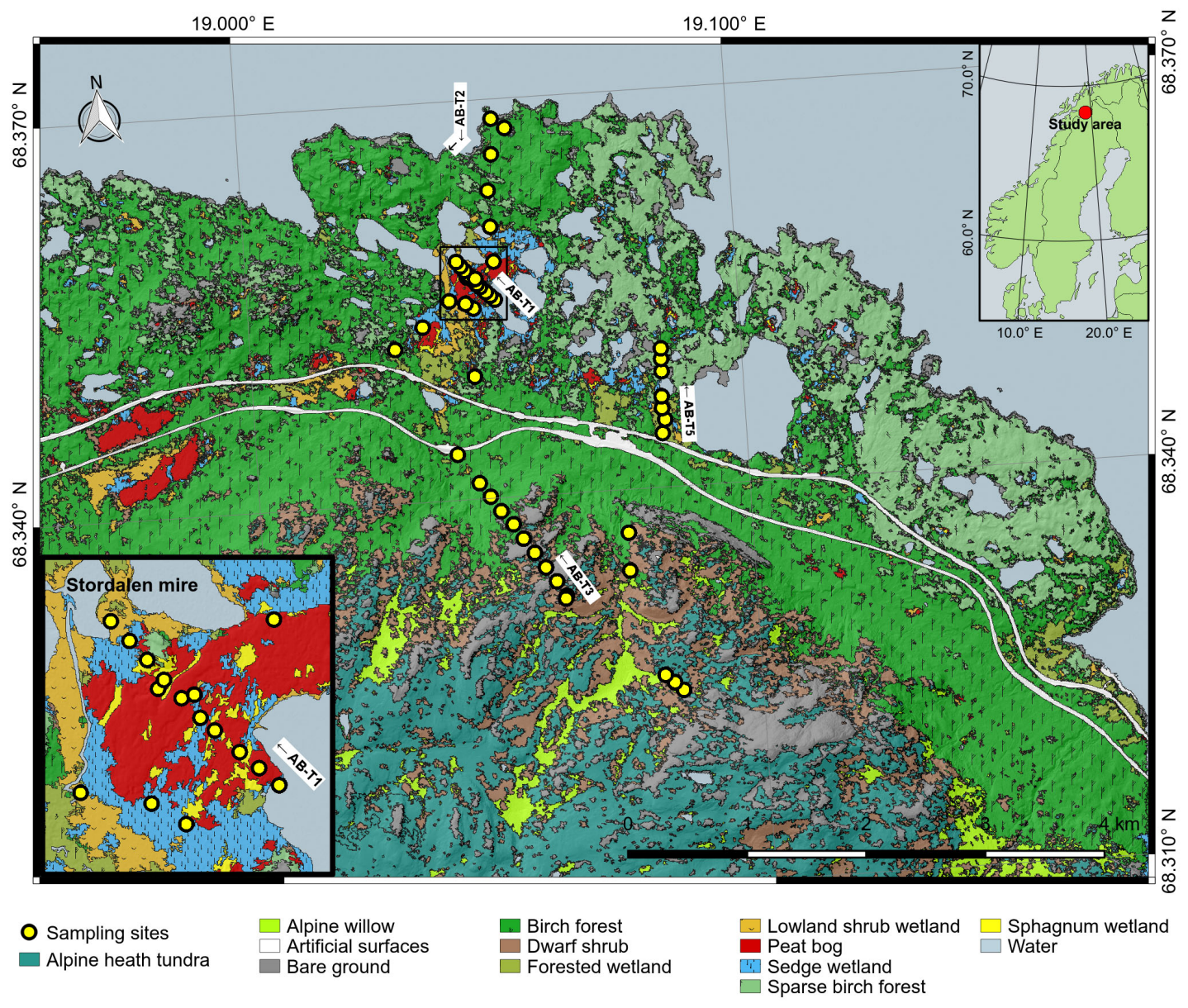

Figure 1. Top right inset showing the location of the study area. Main view showing the land cover classification for the entire mapping extent. The bottom left inset shows a closeup of Stordalen mire. The beginning and counting direction of the four main sampling transects are marked.

to peat mires due to insulation effects of the peat. Here it can be several meters thick below elevated permafrost peat plateaus (palsa; Johansson et al., 2011). At higher elevation, permafrost was modeled to occur above $850 \mathrm{~m}$ a.s.l. on northeast and east-facing slopes and above 1000 to $1100 \mathrm{~m}$ a.s.l. on west and south-facing slopes west of Abisko Scientific Research Station (Ridefelt et al., 2008). Widespread permafrost degradation has occurred at least since the 1980s. This was associated with increased active layer thicknesses, a decrease in permafrost thickness and complete disappearance of permafrost in some areas (Åkerman and Johansson, 2008; Johansson et al., 2011).

Wetland soils in the study area are of organic nature (Histosols). Soils in the surrounding forest have mostly characteristics of Podzols or micro-Podzols with a bleached horizon below the organic surface layer. Alpine soils are often limited to shallow surface organic layers over rock (Leptosols) or very weakly developed soils in unconsolidated slope or moraine material (Regosols). Soils classify as Cryosols if permafrost occurs within $1 \mathrm{~m}$ at higher elevation or when cry- oturbation occurs and permafrost can be detected within $2 \mathrm{~m}$ (FAO, 2015).

\section{Methods}

The workflow of this study is outlined in Fig. 3. First, datasets of environmental predictors and soil pedons are compiled. Second, a LCC of very high spatial resolution at $1 \mathrm{~m}$ (i.e., $1 \times 1 \mathrm{~m}$ ) is generated using a subset of the environmental predictors. Third, digital soil mapping is performed by combining the environmental predictor variables and the soil pedon dataset. For this, four commonly used machinelearning algorithms are tested to generate prediction models of SOC using a regression approach. The best performing model is used to develop high-resolution $(1 \mathrm{~m})$ spatial maps of SOC for different depth intervals. The effect of spatial resolution is analyzed by predicting the SOC with a progressively resampled environmental predictor dataset at resolutions of 2, 10, 30, 100, 250 and $1000 \mathrm{~m}$. The LCC is used for 


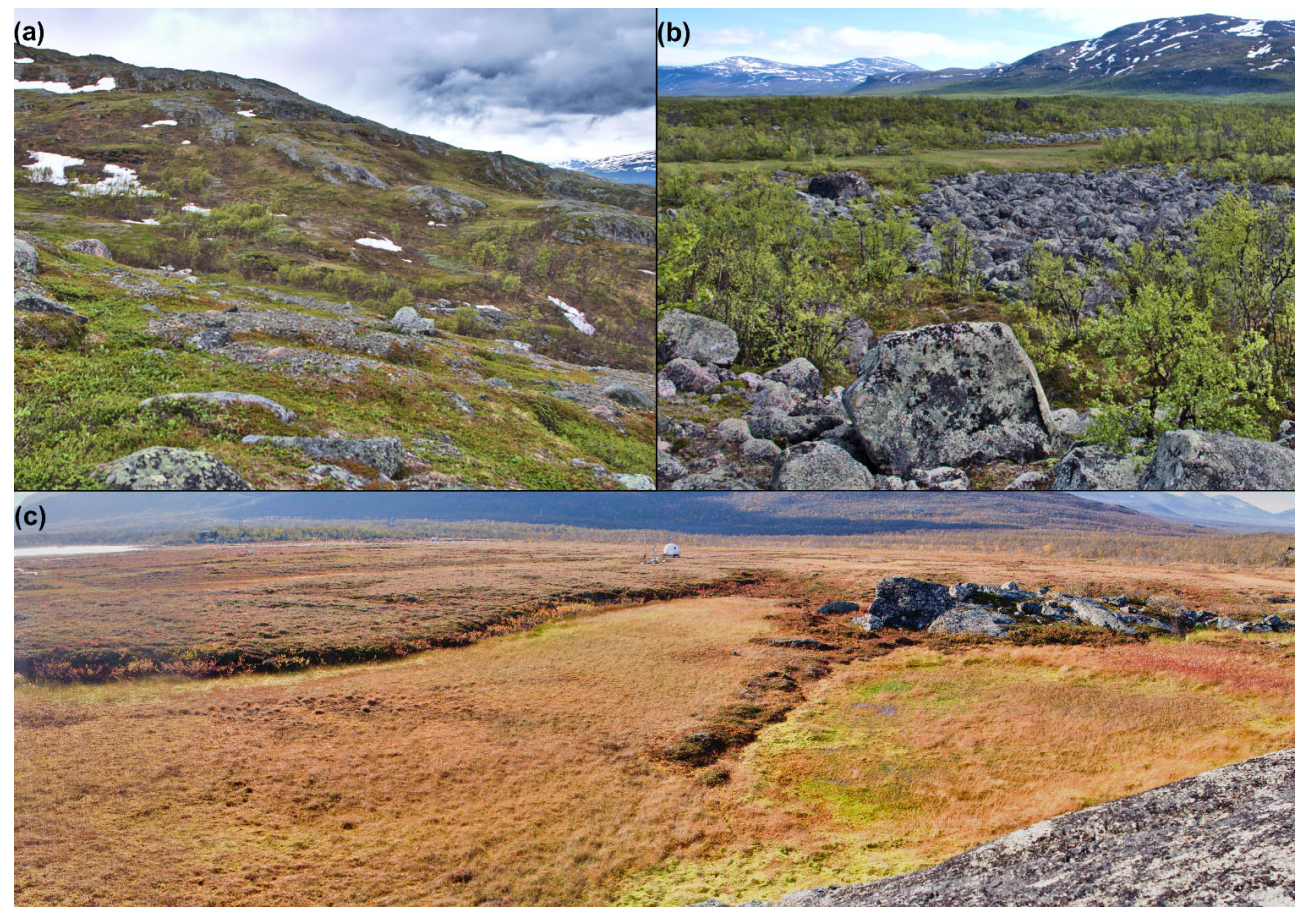

Figure 2. Photographs exemplifying the study area. (a) Alpine landscape mosaic showing several land cover classes including bare ground and alpine tundra heath transitioning into birch forest. (b) Lowland landscape mosaic showing sparse birch forest, blockfields and a small wetland in the direct neighborhood. (c) Raised permafrost peat plateau (left) with sharp transition to Sphagnum-dominated wetland areas and exposed bedrock areas (right).

stratified extraction of the SOC per land cover class. Lastly, radiocarbon samples are analyzed to understand past SOC aggregation.

\subsection{Field survey and SOC data}

Soil sampling was performed in September 2013 and June 2015. In total, 47 sites were sampled following initial field reconnaissance. Sampling was undertaken along four main transects with $8-10$ points of equal distance between 50 to $300 \mathrm{~m}$ (Fig. 1). These transects were laid out as a semirandom sampling scheme to represent major environmental gradients with a restricted amount of sampling points in difficult terrain. The main transects were complemented with smaller transects ( $n=2$ and 3$)$ and six additional profiles from land covers with small patch sizes otherwise not covered. Some transects are incomplete due to points located in lakes, or to avoid disturbance of experimental installations or wildlife.

The sampling procedure followed (Schoeneberger et al., 2012), with an additional protocol for permafrost-affected soils (Ping et al., 2013; Siewert et al., 2016). Sampling in peat was performed in $5 \mathrm{~cm}$ intervals by cutting samples of known volume from the open pit, using fixed-volume cylinders or in case of waterlogged conditions using a fixed-volume Russian peat corer. Sampling in birch forest and tundra was performed according to soil horizons. The organic layer (OL) was sampled completely, while deeper soil horizons were sampled in 5 to $10 \mathrm{~cm}$ intervals depending on horizon thickness. Frozen soil (permafrost) and deep soil layers were sampled by hammering a steel pipe into the ground. Soils outside the peat complexes are in general very shallow, have large volumes of coarse fragments and often become impossible to sample after $\sim 20-50 \mathrm{~cm}$ as the fractured lithic contact is reached. The unsampled coarse fraction consisting of unconsolidated bedrock was noted and used to correct the amount of soil material. For the tundra heath, the OL can be discontinuous with patches of vegetation alternating with patches of bare ground. Here the SOC storage was corrected for the proportional coverage of the OL per squared meter. Each point location was recorded in the field using a hand-held GPS device ( $\pm 5 \mathrm{~m}$ location accuracy).

A total of 278 individual soil samples were collected. Dry bulk density (DBD, $\mathrm{g} \mathrm{cm}^{-3}$ ) was calculated from oven dried soil samples $\left(65^{\circ} \mathrm{C}\right.$ for 5 days). The loss on ignition (LOI) method was performed on all samples at $550{ }^{\circ} \mathrm{C}$ for $5 \mathrm{~h}$ to determine the organic matter content and at $950{ }^{\circ} \mathrm{C}$ for $2 \mathrm{~h}$ to determine the inorganic $\mathrm{C}$ content (Heiri et al., 2001). C\% was measured for a subset of 73 samples using an EA 1110 Elemental Analyzer (CE Instruments, Italy). A further subset of samples with relatively high inorganic $\mathrm{C}$ were acid treated but showed very little reaction. LOI at $950{ }^{\circ} \mathrm{C}$ for all samples also indicated very low inorganic $\mathrm{C}$ content in the soils 


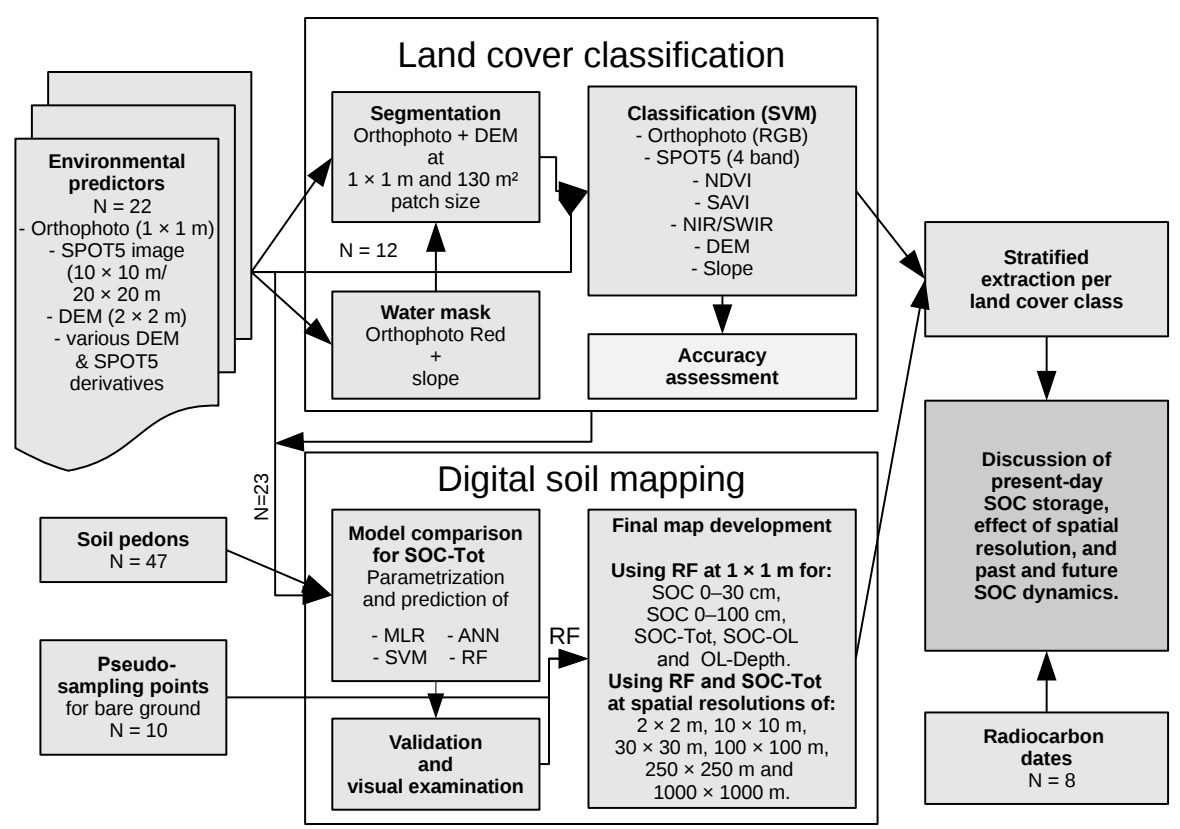

Figure 3. Workflow diagram for this study. Environmental predictor variables are used to generate a land cover classification. Digital soil mapping is performed using soil pedons combined with environmental predictor variables to train prediction models for total SOC (SOCTot). The best performing model (RF) is used to develop maps of different SOC depth increments and the OL depth (supplemented with pseudo-sampling points). The results are discussed, with the help of eight radiocarbon samples, in the context of present-day SOC storage, the effect of spatial resolution, past and future SOC dynamics, and the relevance of wetlands for the SOC storage in permafrost environments.

$(0.73 \pm 0.62 \%)$. Hence, inorganic $\mathrm{C}$ content was not further analyzed. $\mathrm{C} \%$ values were then used to predict $\mathrm{C} \%$ for samples where only LOI was available using a third order polynomial regression model (Fuchs et al., 2015; Hugelius et al., 2011; Siewert et al., 2015). The SOC storage was calculated per soil sample using C\%, DBD, excluding soil material of the coarse fraction (CF, \%; determined by sieving of the sample $>2 \mathrm{~mm}$ ) and sample depth interval. Depth intervals that have not been sampled were gap filled based on soil horizon information. The average pedon depth was $103 \pm 29 \mathrm{~cm}$ for wetland pedons and $26 \pm 27 \mathrm{~cm}$ for non-wetland pedons. To estimate the total SOC (SOC-Tot) stored in the landscape, all wetland pedons were processed to a reference depth of $1.5 \mathrm{~m}$ and non-wetland pedons to a depth of $1 \mathrm{~m}$. If the pedon did not reach that depth it was extrapolated based on a trend in the pedon or similar pedons or set to zero if the lithic contact was reached. Other extracted depth intervals are the SOC stored in the organic surface layer (SOC-OL), the SOC stored for the top $30 \mathrm{~cm}$ (SOC $0-30)$ and the SOC for the top $100 \mathrm{~cm}$ (SOC 0-100). The depth of the organic surface layer (OL-Depth) was also predicted.

To evaluate long-term SOC dynamics, eight samples were submitted for AMS ${ }^{14} \mathrm{C}$ dating to the Radiocarbon Laboratory in Poznan, Poland. The resulting dates were calibrated to calendar years, cal yr BP (1950) using OxCal 4.2 (Bronk Ramsey, 2016).

\subsection{Environmental datasets}

A set of spatially referenced environmental datasets was used as predictors to reflect ecosystem properties in the study area. In the optical domain, an orthophoto of $1 \mathrm{~m}$ spatial resolution with RGB-bands from 2008 (@ Lantmäteriet, I2014/00691) and a SPOT5 orthorectified multispectral satellite image (Path 045, row 208, acquired 10 August 2013) (@ Lantmäteriet, I2014/00691) were available. The spectral bands of the SPOT image include green, red and nearinfrared (NIR) at $10 \mathrm{~m}$ spatial resolution and a shortwaveinfrared (SWIR) band at $20 \mathrm{~m}$ spatial resolution. A topographical correction for differential illumination was applied to the orthophoto and the SPOT image to compensate for terrain shadows using a "Minnaert correction with slope" implementation (Law and Nichol, 2004). The SPOT image was used to derive the normalized difference vegetation index (NDVI; Rouse et al., 1974) and the soil-adjusted vegetation index (SAVI) with an $L$ value of 0.7 (Huete, 1988). Furthermore, the ratio of NIR/SWIR bands was used. A digital elevation model (DEM) of $2 \mathrm{~m}$ spatial resolution (CLantmäteriet, I2014/00691) was used to generate several derivative topographic datasets. These include slope, aspect, profile and plan curvature, topographic ruggedness index (TRI), topographic position index (TPI; Wilson et al., 2007), a TPI-based landform classification (Guisan et al., 1999), and topographic wetness index (TWI) (Moore et al., 
1991). Survey-based vector maps with a scale of $1: 250000$ were obtained for the geology and quaternary land cover (C SGU, I2014/00691) and for vegetation (@ Lantmäteriet, I2014/00691). Geospatial analyses as well as raster and vector processing were performed using GDAL/OGR (GDAL, 2016), SAGA (Conrad et al., 2015), Orfeo toolbox and R (R Core Team, 2017) software (see Code S1 in the Supplement).

\subsection{Land cover classification}

An object-based approach was used to generate a detailed LCC (Blaschke, 2010). Object-based classifications avoid mis-classification of individual pixels that can be problematic with pixel-based classifications at very high resolution. This reduces the need for post-processing, filtering and other generalization methods otherwise necessary (Siewert et al., 2015). The LCC is used as a predictor variable and for stratified extraction of the digital soil mapping results. First, the orthophoto was combined with the DEM resampled to $1 \mathrm{~m}$ spatial resolution. A segmentation layer was generated by grouping pixels into homogeneous areas with a minimum region size of $130 \mathrm{~m}^{2}$. From this, a water mask was classified using the red band of the orthophoto and a slope layer. A land cover training set was created by combining field survey information with visual interpretation of the orthophoto and topography. The following layers were used as input for the classification algorithm: the orthophoto, elevation and slope; the SPOT5 4-band satellite image and NDVI (Rouse et al., 1974), SAVI (Huete, 1988) and NIR/SWIR (SPOT5 derivatives). The ratio of the NIR/SWIR band can be beneficial to separate bedrock and bare rock areas (Andersson, 2016). The segments were then classified using a support vector machine (SVM; Chang and Lin, 2011) algorithm. Artificial surfaces were manually digitized and masked out. The individual thematic classes were adapted from Andersson (2016) and are described in Table S1 in the Supplement.

The quality of the classification was assessed using a set of 108 ground control points. These include the locations of the soil sampling sites and points along pathways collected at equal distance from the starting point. The kappa coefficient and the overall accuracy were calculated for all land covers excluding water and artificial areas (Congalton, 1991).

\subsection{Digital soil mapping using machine learning}

Numerous machine-learning algorithms and approaches exist. A comprehensive general overview on machine-learning techniques is provided by Hastie et al. (2009) and the use of different machine-learning algorithms for digital soil mapping is thoroughly discussed for instance in McBratney et al. (2003), Li et al. (2011), Were et al. (2015) and Taghizadeh-Mehrjardi et al. (2016). Thus, only a brief description follows. Four commonly used machine-learning techniques were compared: a multiple linear regression (MLR) model, an artificial neural network (ANN; Ripley,
1996), a support vector machine (SVM; Chang and Lin, 2011) and random forest (RF; Breiman, 2001).

Multiple linear regression (MLR) assumes that the regression function defining the soil variable is linear or can be approximated using a linear equation. The soil variable $f(x)$ represents the dependent variable and the environmental predictors represent the independent variables $X_{i}$, where $a$ is the intercept and $b_{i}$ are regression coefficients.

$$
f(X)=a+\sum_{i=0}^{n} b_{i} x_{i}
$$

The training data are used to define the regression equation and then used to predict the soil variable for unseen occurrences in the environmental space. MLR is a popular technique that is comparatively simple. It is possible for linear regression models to outperform non-linear methods in situations with limited input data and low signal-to-noise ratio (Forkuor et al., 2017; Hastie et al., 2009).

For the MLR model the $l m$ function in $\mathrm{R}$ was used ( $\mathrm{R}$ Core Team, 2017). A model was trained using 10 -fold crossvalidation with five repetitions to develop a stable model of SOC-Tot using the "caret" R package (Forkuor et al., 2017; Kuhn, 2008b).

Artificial neural network $(A N N)$ is a technique that simulates the biological nervous system. For continuous soil variables, it is a two-stage regression model typically represented by a network diagram with three layers. A layer of input cells represents environmental covariates and is connected to a layer of hidden cells, which is connected to an output layer representing the soil property to be predicted. These connections, also called weights or synapses, form a network that defines the model. The model simulates learning from examples by training the network iteratively with information about the conditions in which a certain value of the soil variable occurs. During each iteration the connection between the input layer, hidden layer and the output unit is adjusted. Finally, the trained model is used to predict soil properties of unvisited pixels (Behrens et al., 2005; Hastie et al., 2009).

The ANN was parameterized using a grid-search approach for the variables defining the size of the hidden layer and the decay of weights in the neural network. The tuning was started with a value of 2 for size to avoid a local minimum. The "caret" $\mathrm{R}$ package was used in combination with a 10fold cross-validation with five repetitions to fit a stable model of SOC-Tot based on the smallest RMSE value (Forkuor et al., 2017; Kuhn, 2008b).

Support vector machine (SVM) is a technique that generates an optimal separating hyperplane to differentiate classes that overlap and are not separable in a linear way. In this case, a large transformed feature space is created to map the data with the help of kernel functions to separate it along a linear boundary. While initially developed for classification purposes, this technique can also be used for regression problems (Hastie et al., 2009; Vapnik, 1998). 
For SVM, a $\varepsilon$-regression with a gaussian radial basis kernel was used. This kernel can be considered a good general purpose kernel (Zeileis et al., 2004). The cost parameter $C$ and the $\varepsilon$ error threshold parameter were determined using the grid-search method. The final model was developed using 10 -fold cross-validation with five repetitions implemented by the "caret" package in R (Forkuor et al., 2017; Kuhn, 2008b).

Random Forest $(R F)$ is a tree-based learner that combines decision-tree and bagging methods (Breiman, 2001). RF draws a number of bootstrap samples ( $\left.n_{\text {tree }}\right)$ from the input dataset representing individual soil samples and grows a large amount of unpruned regression trees (e.g., 500), where at each node random samples $\left(m_{\text {try }}\right)$ of the environmental predictors are chosen. It then averages the prediction of all trees to predict new data (Liaw and Wiener, 2002).

For RF, the "randomForest" R package was used (Liaw and Wiener, 2002). A value of 7 for $m_{\text {try }}$ equaling the $\sim 3$ /predictors, a node size of 5 and $n_{\text {tree }}=100$ provided stable and visually meaningful results. Different variations in the parameters $m_{\text {try }}, n_{\text {tree }}$, node size and maximum node number were tested. However, these generated visually inferior results while providing only minor improvements to $R^{2}$ or increased the dependency of the most important predictive variable indicating overfitting. Sampling was performed with replacement, and bias correction was applied to decrease overestimation for low values and underestimation for high values. To achieve stable model results, a 10-fold crossvalidation with five repetitions was applied (Forkuor et al., 2017; Kuhn, 2008b).

\subsection{Model selection and validation}

Originally, all models overestimated SOC contents for bare ground surfaces. These areas include exposed bedrock, blockfields (areas covered by shattered rock fragments with little or no fine substrate; Fig. 2b) and stone beaches along lake shores (alpine heath tundra with minimal soil development and cryogenic features forms a separate class). To address the overestimation, 10 pseudo-training samples of $0.0 \mathrm{~kg} \mathrm{C} \mathrm{m}^{-2}$ SOC were added at bare ground locations. These were based on field knowledge and were identified in the orthophoto. They were distributed across the study area and kept at a low number to avoid strong bias of the training dataset. A similar approach has been used by Siewert et al. (2012) to support spatial interpolation of limited line measurements to estimate the sediment thickness of talus cones.

The ability of all four machine-learning algorithms (MLR, ANN, SVM and RF) to predict SOC-Tot was tested by training each model with the soil pedon dataset (excluding pseudo-training samples). The models were evaluated based on three commonly used error criteria derived by crossvalidation (leave one out method): the coefficient of determination $\left(R^{2}\right)$, the root mean squared error (RMSE) and Lin's concordance correlation coefficient (CCC; Lin, 1989). $R^{2}$ is an indicator of model precision, while RMSE is an indicator of accuracy and CCC combines measures of accuracy and precision to determine the agreement to a $45^{\circ}$ line. Maps were developed by applying the predictive models to the environmental datasets. These were then visually examined and compared to a thematic map of the SOC storage based on the combination of the LCC and average SOC values of soil pedons per LCC class.

For the final analysis, the best performing algorithm (RF) was chosen to model and develop maps for each of the following soil variables: SOC-OL, SOC 0-30, SOC 0-100, SOC-Tot and the OL-Depth at a spatial resolution of $1 \mathrm{~m}$. To investigate potential circumpolar SOC mapping efforts, the SOC-Tot was also mapped at spatial resolutions of 2, 10, $30,100,250$ and $1000 \mathrm{~m}$ by resampling the spatial predictor dataset. Hugelius (2012) provides a similar approach using thematic mapping. These resolutions aim to mimic commonly used and freely available satellite data, e.g., Sentinel$2(10 \mathrm{~m})$, Landsat $(30 \mathrm{~m})$, Moderate Resolution Imaging Spectroradiometer (MODIS, 250-1000 m) and the Advanced Very High Resolution Radiometer (AVHRR, 1100 m). They also represent common resolutions for Earth system model applications. The SOC was then extracted using the $1 \mathrm{~m}$ resolution LCC. Multicollinearity among the predictor variables was analyzed using a correlation matrix. Variables with a correlation $>0.90$ were excluded (Kuhn, 2008a). Finally, predicted SOC values below 0 were set to 0 .

\section{Results}

\subsection{Land cover classification}

The LCC showed good agreement with the classes that have been observed in the field and areas that have been visually identified in the orthophoto (Fig. 4a and b). The accuracy assessment results in a kappa value of 0.71 and an overall accuracy of $74 \%$ (Table S2). These values are comparable to other high-latitude LCC accuracy assessments (Schneider et al., 2009; Siewert et al., 2015; Virtanen et al., 2004; Virtanen and Ek, 2014). The object-based classification has a minimum patch size of $130 \mathrm{~m}^{2}$. This size was found to best differentiate areas of homogeneous land cover, while preserving characteristic shapes of landforms relevant for SOC storage in high latitudes, such as peat plateaus.

\subsection{Performance of four machine-learning algorithms to predict SOC}

Four different models were compared to predict SOC-Tot stocks (Fig. 5). There were large discrepancies between the models. RF achieved the highest coefficient of determination $\left(R^{2}, 0.736\right)$ and CCC $(0.572)$, while having the lowest root mean squared error (RMSE, 14.131). This indicates high precision $\left(R^{2}\right)$, good agreement with the $45^{\circ}$ line (CCC) and high accuracy (RMSE). This was followed by SVM with a slightly inferior performance for each er- 

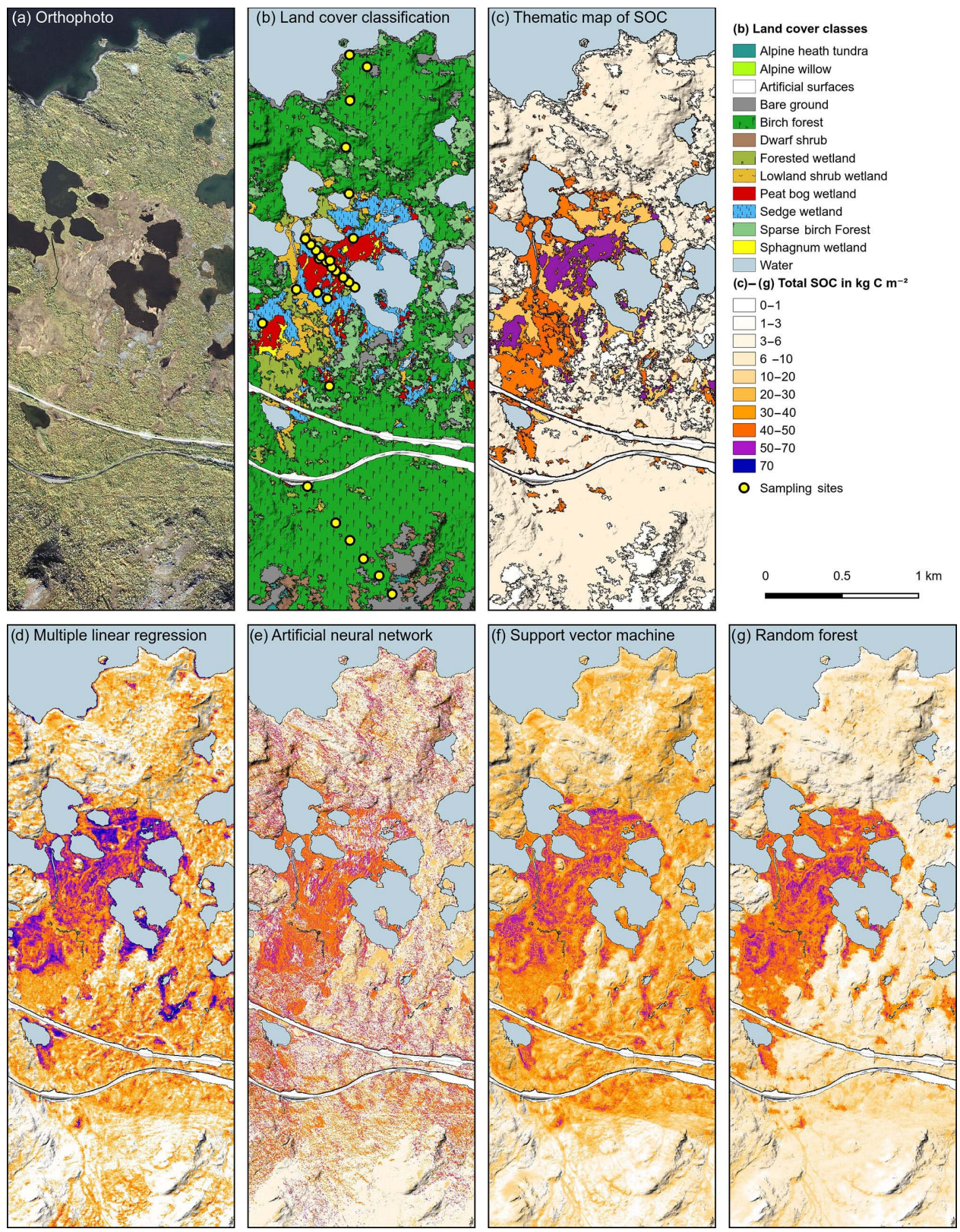

Figure 4. A close up of the area near Stordalen mire comparing different maps. (a) Illumination-corrected orthophoto (@ Lantmäteriet, I2014/00691). (b) Land cover classification, (c) soil organic carbon (SOC) storage using a thematic mapping approach. (d-g) Maps developed using different machine-learning models. Each map uses all input soil pedons and pseudo-sampling points; (d) multiple linear regression model (MLR), (e) artificial neural network (ANN), (f) support vector machine (SVM) and (g) random forest (RF).

ror criterium $\left(R^{2}=0.726, \mathrm{CCC}=0.543, \mathrm{RMSE}=14.9\right)$. MLR and ANN showed a significantly higher deviation of predicted to sampled SOC values (MLR: $R^{2}=$ $0.48, \mathrm{CCC}=0.418, \mathrm{RMSE}=21.22 ; \mathrm{ANN}: R^{2}=0.533$, $\mathrm{CCC}=0.483, \mathrm{RMSE}=17.614)$.

All models underestimate high values and overestimate low values of SOC-Tot (Fig. 5). This so called regression to mean effect is a known shortcoming. For the RF algorithm it was addressed using the bias correction option in the "ran-
domForest" package (Liaw and Wiener, 2002; Zhang and Lu, 2012). Yet, a slight overestimation for low values from $\sim 0$ to $25 \mathrm{~kg} \mathrm{C} \mathrm{m}^{-2}$ and an underestimation for SOC-Tot values above $\sim 60 \mathrm{~kg} \mathrm{C} \mathrm{m}^{-2}$ remains.

The developed output maps show significant differences for the four prediction models (Fig. $4 \mathrm{~d}-\mathrm{g}$ ). Major wetland areas can be recognized in all four maps. The MLR model (Fig. 4d) shows a strong contrast in SOC storage with sharp transitions between wetland and non-wetland areas. SOC 


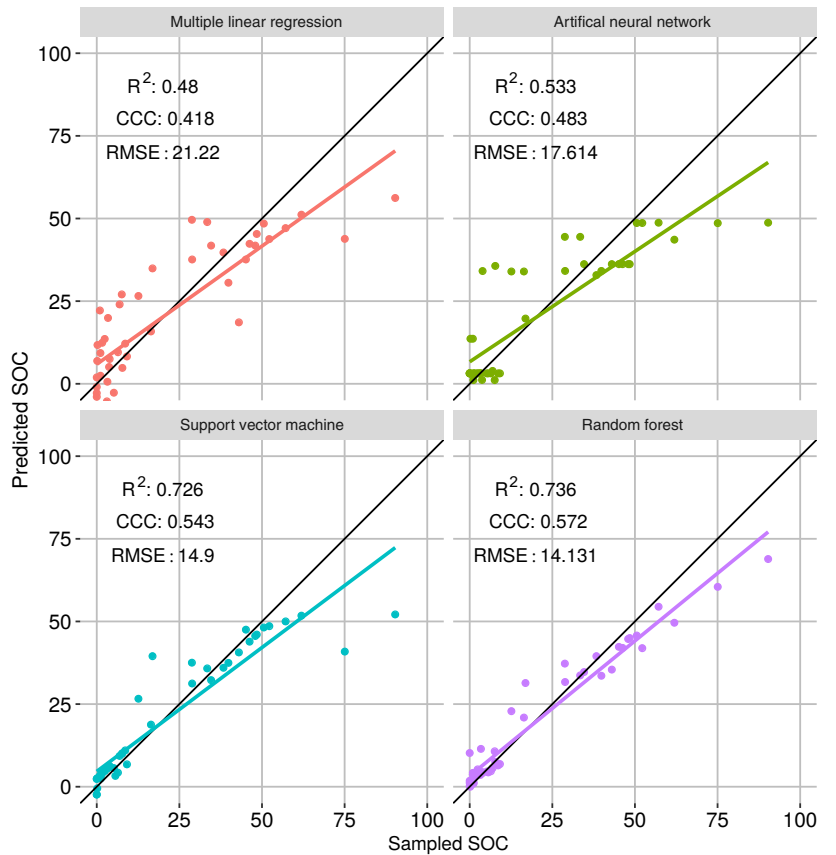

Figure 5. Performance of different prediction models developed using the soil pedon dataset excluding pseudo-training samples. The evaluation is based on observed against predicted total soil organic carbon (SOC) values. The performance metrics are based on crossvalidation $\left(R^{2}\right.$ : coefficient of determination, CCC: Lin's concordance correlation coefficient (CCC) and RMSE: root mean squared error).

storage in non-wetland areas seems to be overestimated. Wetland areas are predicted to have a very high SOC storage throughout, corresponding well to the thematic map (Fig. 4c). The ANN model (Fig. 4e) does not generalize well to the field situation. While it differentiates well between wetland and non-wetland areas, it also exhibits a significant amount of noise with unrealistically high values in birch forest. Wetland areas show low values compared to the other models. SVM and RF visually correspond best to the field situation of sampled and analyzed soils as exemplified in the thematic map of SOC (Fig. 4c, g, f). SVM overestimates low SOC values for lowland birch forest and bare ground areas (Fig. 4f). RF replicates the extent of elevated peat bogs and plateaus slightly better than SVM and MLR (Figs. 2 and 4dg). RF and MLR perform best at representing low SOC values of bare ground areas and blockfields.

\subsection{Environmental controls on SOC distribution}

As the RF model provided the best performance for the error metrics and the visual evaluation, the remaining analysis proceeds using only RF. The importance of each input variable for the prediction of the SOC-Tot at $1 \mathrm{~m}$ resolution is presented in Fig. 6. The LCC is the most important predictive variable. This is followed by TWI, a group of SPOT-5-based

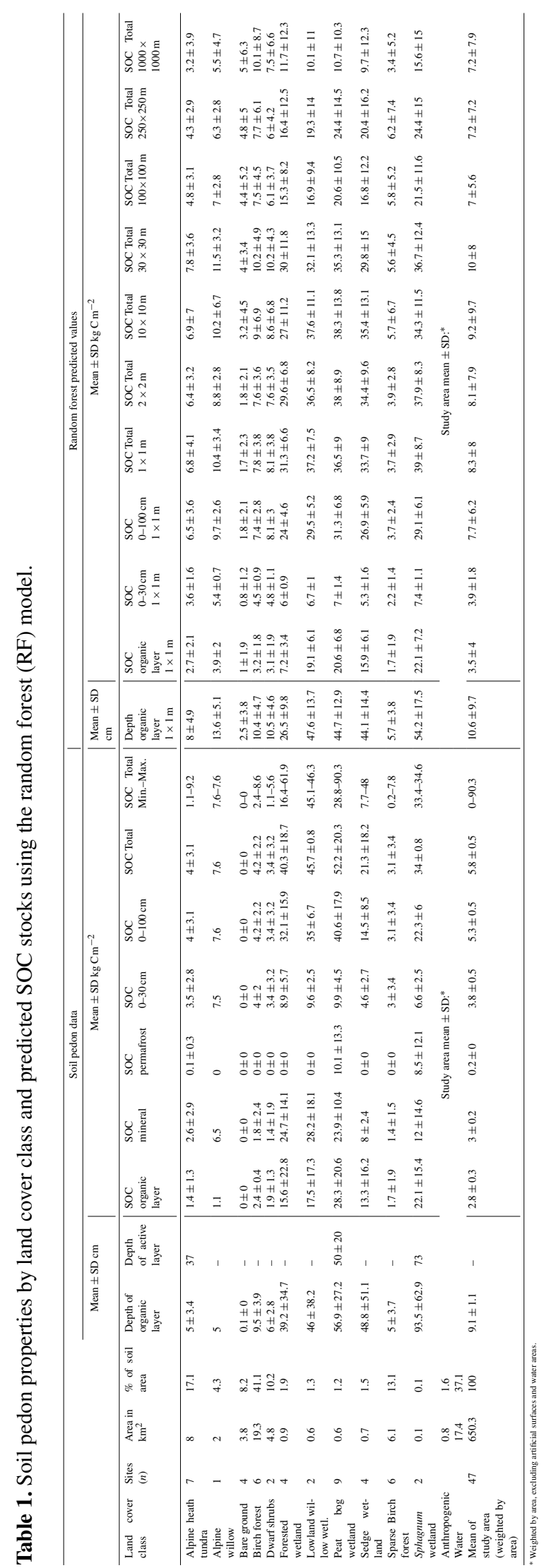

Biogeosciences, 15, 1663-1682, 2018 


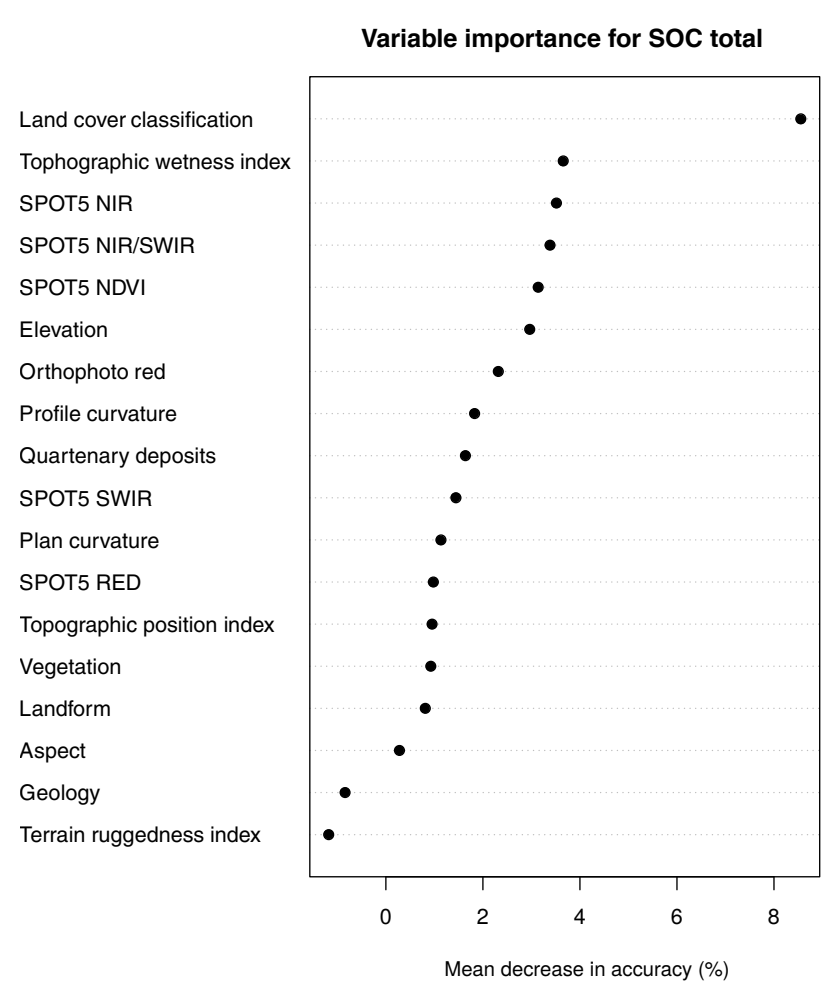

Figure 6. Variable importance for the prediction of total SOC measured as mean decrease in accuracy of the random forest model if the variable is excluded. The higher the value the more important is the variable.

input variables and elevation. The SPOT5 variables include the NIR band, the ratio of NIR/SWIR and NDVI. Other variables have limited predictive power and five variables were excluded after testing for multicollinearity.

The variable importance changes for the individual prediction models of SOC 0-30, SOC 0-100, SOC-OL, OL-Depth (Fig. S1) and SOC-Tot. However, the pattern usually resembles that of SOC-Tot (Fig. 6). Land cover is the most important environmental variable in all models except for SOC 0 30 , where NIR/SWIR is the most important variable followed by NDVI, LCC and NIR.

\subsection{SOC stocks and landscape partitioning}

Table 1 shows the landscape partitioning of the sampled SOC pedon values and the predicted SOC values using machine learning. The landscape mean SOCTot storage is predicted to be $8.3 \pm 8.0 \mathrm{~kg} \mathrm{C} \mathrm{m}^{-2}$ and $7.7 \pm 6.2 \mathrm{~kg} \mathrm{C} \mathrm{m}^{-2}$ for the top meter (SOC 0-100) of soil. This compares to $5.8 \pm 0.5 \mathrm{~kg} \mathrm{C} \mathrm{m}^{-2}$ for the SOC-Tot and $5.3 \pm 0.5 \mathrm{~kg} \mathrm{C} \mathrm{m}^{-2}$ for the interval $0-100 \mathrm{~cm}$ using the LCC for thematic mapping. The highest SOC stock per class is estimated for the Sphagnum covered wetland areas $\left(39.0 \pm 8.7 \mathrm{~kg} \mathrm{C} \mathrm{m}^{-2}\right)$ followed by the other wetland classes: peat bog $\left(36.5 \pm 9.0 \mathrm{~kg} \mathrm{Cm}^{-2}\right)$, lowland shrub wetland $\left(37.2 \pm 7.5 \mathrm{~kg} \mathrm{C} \mathrm{m}^{-2}\right)$, sedge wetland $\left(33.7 \pm 9.0 \mathrm{~kg} \mathrm{Cm}^{-2}\right)$ and forested wetland $\left(31.3 \pm 6.6 \mathrm{~kg} \mathrm{C} \mathrm{m}^{-2}\right)$. The alpine willow class stores the highest amount of SOC of the remaining non-wetland classes with $10.4 \pm 3.4 \mathrm{~kg} \mathrm{C} \mathrm{m}^{-2}$, followed by birch forest $\left(7.8 \pm 3.8 \mathrm{~kg} \mathrm{C} \mathrm{m}^{-2}\right)$ and dwarf-shrubs $\left(8.1 \pm 3.8 \mathrm{~kg} \mathrm{C} \mathrm{m}^{-2}\right)$. The bare ground class stores the lowest amount of SOC with $1.7 \pm 2.3 \mathrm{~kg} \mathrm{C} \mathrm{m}^{-2}$. This represents most likely an overestimation and should be close to $<0.1 \mathrm{~kg} \mathrm{C} \mathrm{m}^{-2}$. For SOC-OL, SOC $0-30$ and SOC $0-$ 100 similar patterns emerge. Permafrost was encountered in six pedons of which four were located in peat bog with an average depth of $50 \pm 20 \mathrm{~cm}$, one in the Sphagnum wetlands and one alpine tundra heath. The mire permafrost soils were sampled in early September in 2013, while the alpine heath tundra $(\mathrm{AL}-\mathrm{Depth}=37 \mathrm{~cm})$ pedon was sampled in June and does not represent maximum annual active layer depth. The partition of SOC stored in permafrost is $10.1 \pm 13.3 \mathrm{~kg} \mathrm{C} \mathrm{m}^{-2}$ for peat bog soils and $8.5 \pm 12.1 \mathrm{~kg} \mathrm{C} \mathrm{m}^{-2}$ for Sphagnum wetland soils. This equals $0.2 \pm 0.0 \mathrm{~kg} \mathrm{C} \mathrm{m}^{-2}$ of the total landscape SOC weighted by area using thematic mapping. Prediction of the SOC in permafrost did not yield sound results (data not shown). The predicted depth of the OL compares well to sampled depths except for Sphagnum and forested wetlands, where it underestimates mean depth and for alpine willow class, where it approximately doubles the pedon mean.

The relative landscape SOC storage partitioning is shown in Fig. 7. Birch forest stores $38 \%$ of the SOC-Tot covering $41 \%$ of the soil area. This is followed by alpine heath tundra that stores $14 \%$ of the SOC on $17 \%$ of the area. Wetlands store $25 \%$ of the SOC-Tot while only covering \% of the landscape. The individual wetland classes have the highest ratio of stored SOC (5.4-7.1\%) compared to the area covered (1.2-1.8\%) (except Sphagnum wetland, where the ratio is $0.6 \%$ SOC to $0.1 \%$ of the area), while bare ground has the lowest ratio covering $8 \%$ of the area and storing only $1.6 \%$ of the SOC.

\subsection{Effect of reduced spatial resolution}

The effect of a reduced spatial resolution on the estimate of landscape mean SOC-Tot storage and partitioning is presented in Fig. 8, Table 1 and Fig S2 in the Supplement. The estimate of SOC-Tot first increases from $8.3 \pm 8.0 \mathrm{~kg} \mathrm{C} \mathrm{m}^{-2}$ at a resolution of $1 \mathrm{~m}$ to $10 \pm 8.0 \mathrm{~kg} \mathrm{C} \mathrm{m}^{-2}$ at a resolution of $30 \mathrm{~m}$. At resolutions of 100,250 and $1000 \mathrm{~m}$, the estimate drops to values between $7 \pm 5.6$ and $7.2 \pm 7.9 \mathrm{~kg} \mathrm{C} \mathrm{m}^{-2}$. This decrease is associated with a considerable drop in the estimate of SOC stored in wetland classes, while nonwetland classes do not change significantly in SOC estimates. The model at $10 \mathrm{~m}$ resolution has the highest $R^{2}$ with 0.777 (using $47+10$ pedons), followed by the models at $1 \mathrm{~m}\left(R^{2}=0.759\right), 2 \mathrm{~m}\left(R^{2}=0.752\right)$ and $30 \mathrm{~m}\left(R^{2}=0.733\right)$. The models at resolutions of 100,250 and $1000 \mathrm{~m}$ have an $R^{2}$ between 0.520 and 0.538 (Fig. 8). The predicted maps 


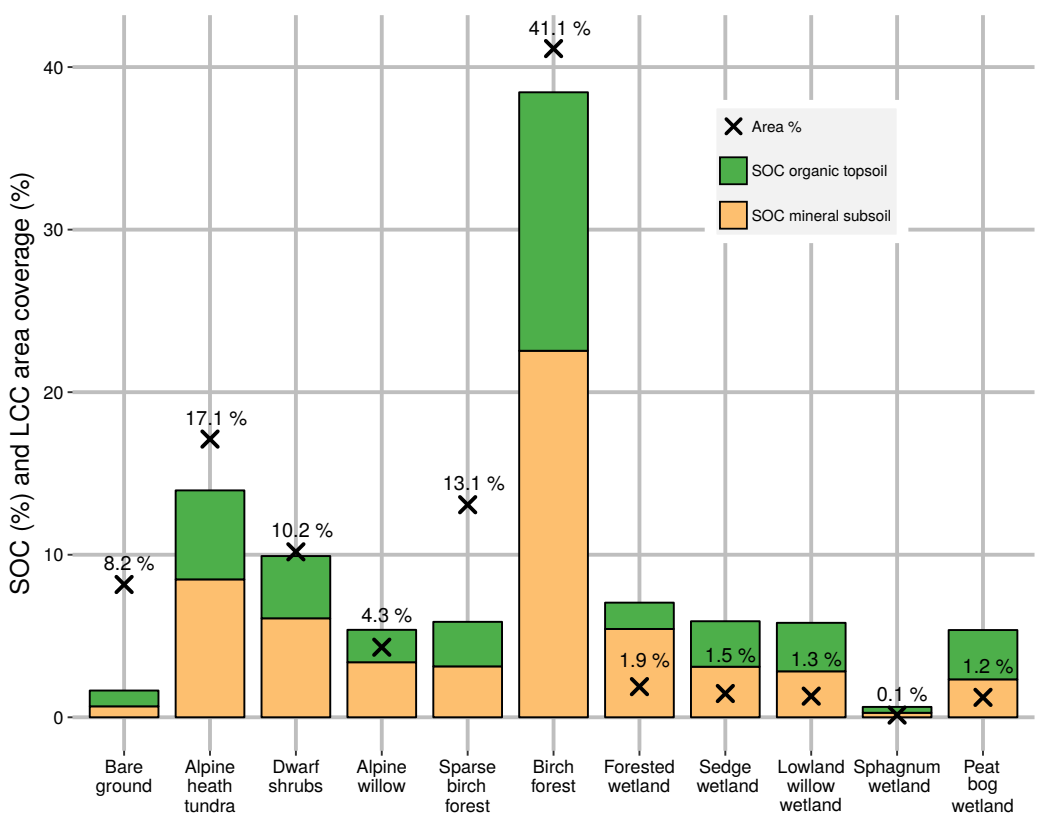

Figure 7. Partitioning of modeled total soil organic carbon (SOC) storage and respective land cover class coverage in \% using a random forest predictor. The height of the column represents the fraction of the SOC-Tot. The mineral SOC is the amount of SOC-OL subtracted from the SOC-Tot. Crosses indicate the percentage areal coverage of the respective land cover class of the total landscape soil area.

show how SOC values are progressively less detailed and the strong contrast between wetland areas and the surrounding disappears. Each resolution emphasizes different details, e.g., SOC in alpine willow shrubs are most pronounced at a resolution of $10 \mathrm{~m}$ (Fig. S2).

\subsection{SOC history and age}

Eight samples have been radiocarbon dated to understand long-term $\mathrm{C}$ dynamics (Table 2). The oldest sample from the central mire indicates a transition from $\mathrm{C}$ enriched mineral sediments to organic peat at $5218 \mathrm{cal} \mathrm{BP}$. A second phase of increased peat accumulation was dated to $2230-1936 \mathrm{cal}$ BP based on a profile close to a lake and in a profile in ombrotrophic waterlogged Sphagnum patch in the center of Stordalen mire. Furthermore, one sample indicates a marked change in peat composition at $150.84 \pm 0.36 \mathrm{pMC}$ (percent modern carbon) for the mire center, which likely corresponds to a change from poor fen to palsa peat accumulation. This is probably related to permafrost formation (Kokfelt et al., 2010). A shallow soil pedon with $\sim 31 \mathrm{~cm}$ depth in alpine birch forest located at mid-slope position was dated with two samples. The base of the OL was dated to modern age and the mineral subsoil at a depth of $22-28 \mathrm{~cm}$ was dated to $150 \mathrm{cal}$ BP. In birch forest located at the footslope, the base of the OL has a modern age and soil at a depth of $20-26 \mathrm{~cm}$ was dated to 1345 cal BP.

\section{Discussion}

\subsection{Predicting SOC using machine-learning algorithms}

Of the compared prediction algorithms, the RF algorithm clearly performed best. This applies to all three error criteria: $R^{2}, \mathrm{CCC}$ and RMSE, as well as to the visual evaluation. On visual comparison, RF was the only algorithm that could reflect the expected distribution of SOC following simple thematic mapping, and also replicate SOC storage defining landforms, i.e., peat plateaus, realistically (Fig. 5). SVM also provided good results, but there was a significant drop in quality for MLR and ANN. The advantage of tree-based machine-learning techniques such as RF is that they can cope well with non-linearity and have minimal assumptions about the data (McBratney et al., 2003). This is an important property, as in the northern circumpolar permafrost region only limited environmental datasets of varying quality are available. ANN and SVM are also non-linear methods, but do not seem to match the result of the tree-based method. The RF model has shown superior performance for regression applications in many environments (e.g., Forkuor et al., 2017; $\mathrm{Li}$ et al., 2011). However, in some environments other models outperformed RF, for example SVM (Were et al., 2015) or ANN (Taghizadeh-Mehrjardi et al., 2016). This indicates that different machine-learning algorithms might suit different landscapes and that several algorithms should be compared (Forkuor et al., 2017).

This study highlights two distinctive and related localscale properties of high-latitude permafrost ecosystems. 


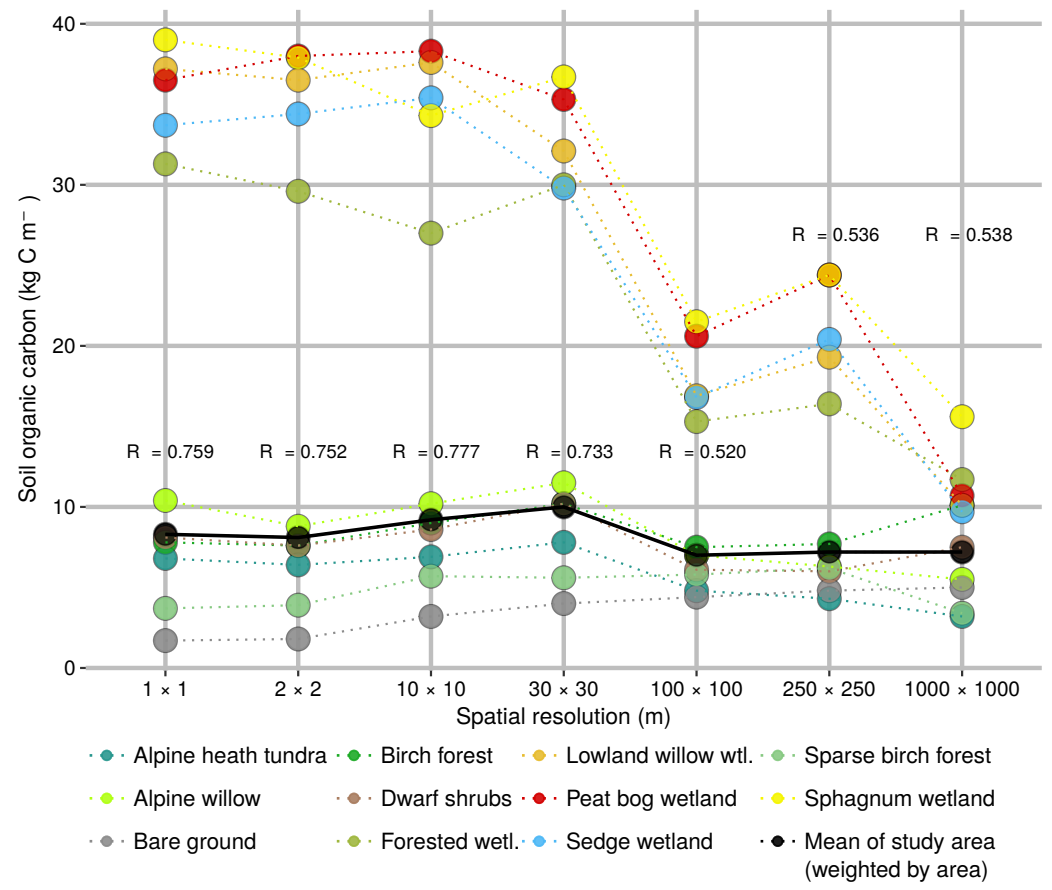

Figure 8. Summary of the predicted soil organic carbon (SOC) at different spatial resolutions. The dots show the development of the SOCTot, while the colored dots show the SOC stored in individual classes extracted using the LCC at $1 \mathrm{~m}$ spatial resolution. The $R^{2}$ values are estimated using the full pedon dataset including pseudo-sampling points.

Table 2. Summary of radiocarbon dating.

\begin{tabular}{llllll}
\hline Soil pedon & Depth & Sample description & Lab. no. ${ }^{\mathrm{a}}$ & Age $^{14} \mathrm{C}$ & Age cal BP $(\mathrm{yr})^{\mathrm{b}}$ \\
\hline AB-T1-06 & $14-15 \mathrm{~cm}$ & Palsa, base of marked change in peat composition & Poz-59879 & $150.84 \pm 0.36 \mathrm{pMC}^{\mathrm{c}}$ & modern \\
AB-T1-06 & $94-95 \mathrm{~cm}$ & Palsa, base of pure peat organics & Poz-59880 & $4565 \pm 30 \mathrm{BP}$ & 5218 \\
AB-T1-10 & $72-73 \mathrm{~cm}$ & Lowland shrub wetland, base of OL & Poz-59882 & $2215 \pm 30 \mathrm{BP}$ & 2230 \\
AB-T2-06 & $48-49 \mathrm{~cm}$ & Sphagnum patch, base of OL & Poz-59883 & $1985 \pm 30 \mathrm{BP}$ & 1936 \\
AB-T3-07 & $11-12 \mathrm{~cm}$ & Alpine birch forest, base of OL & Poz-59884 & $119.16 \pm 0.33 \mathrm{pMC}$ & modern \\
AB-T3-07 & $22-28 \mathrm{~cm}$ & Alpine birch forest, mineral subsoil & Poz-59885 & $150 \pm 30 \mathrm{BP}$ & 150 \\
AB-T3-09 & $18-19 \mathrm{~cm}$ & Birch, base of OL & Poz-59886 & $100.82 \pm 0.29$ pMC & modern \\
AB-T3-09 & $20-26 \mathrm{~cm}$ & Birch forest, mineral subsoil & Poz-59887 & $1455 \pm 30 \mathrm{BP}$ & 1345 \\
\hline
\end{tabular}

${ }^{a}$ Laboratory number of the Radiocarbon Laboratory in Poznań, Poland. ${ }^{b}$ Mean age at $95.4 \%$ probability expressed in calendar years before $1950 .{ }^{c}$ percent modern carbon.

These need to be considered when choosing an appropriate spatial prediction method. One factor is the strong land cover fragmentation of tundra environments with very small land cover patch sizes (Virtanen and Ek, 2014). In the study area, this is reflected in the occurrence of blockfields, small mires and peat plateaus (Fig. 2). The second factor is a high spatial variability in soil properties and thus SOC storage, related to the presence or absence of permafrost, peatlands and meterscale periglacial landforms. For example, blockfields are areas with SOC-Tot stocks of $<0.1 \mathrm{~kg} \mathrm{C} \mathrm{m}^{-2}$. These are often surrounded by forested areas with around $\sim 2-9 \mathrm{~kg} \mathrm{C} \mathrm{m}^{-2}$ or in the direct neighborhood of mire ecosystems with SOCTot stocks of $\sim 10-90 \mathrm{~kg}$ (Table 1). These sharp transitions in SOC storage between different land covers suggest low spatial autocorrelation at a local scale, i.e., little relationship in SOC values between points far apart. Mishra and Riley (2012) showed that geographically weighted regression (GWR), which is based on spatial autocorrelation, can successfully be used to predict SOC stocks at a regional scale in Alaska with a spatial resolution of $60 \mathrm{~m}$. However, permafrost environments can be very variable at a local scale. In areas with ice-wedge polygons, common in lowland tundra environments, the local-scale variability of SOC can be even higher than in Abisko, with SOC values from almost zero on polygon rims to several tens of kilograms in polygon centers on distances of a few meters (Ping et al., 2013, 2015; Siewert et al., 2015, 2016). Thus, any applied machine-learning approach must be able to cope with sharp and non-linear transi- 
tions in SOC storage, while efforts based on spatial autocorrelation may fail at a local scale unless they are supported by highly resolved environmental variables and a substantially higher number of soil pedons than usually available.

In Abisko, the distribution of SOC is defined by the occurrence of peatlands (Figs. 5 and 8), to the extent that two separate populations of soil pedons can be identified (Table 1). This strong non-linearity may be the reason why some predictive models perform better. In the future, it should be tested if in such a case, separate models for different populations of soil pedons can improve the prediction.

\subsection{Limitations, sources of error and uncertainty}

Several sources of error for the predicted SOC values can be identified. One source of uncertainty is related to the amount of sampled soil pedons and limitations of transect sampling as opposed to ideal random sampling. Given the difficult nature of Arctic and mountainous environments, transect sampling is the most time efficient data collection method providing sufficient amounts of soil pedons for regression analysis. Most sub-Arctic and Arctic research facilities are located in remote areas and logistics are difficult, thus the main source of uncertainty in many local- and regional-scale studies on SOC distribution is the low number of available soil data with often only $\sim 10-50$ pedons. The results show that machinelearning predictions using few soil pedons $(n=47+10)$ can provide sound results. However, the amount of soil pedons should ideally not be lower. Also, the importance to sample the entire environmental gradient of a study area, including end-members with very low and very high values in soil surveys needs to be underlined. The original dataset included only few data points for the lower range of SOC-Tot values close to $<0.1 \mathrm{~kg} \mathrm{C} \mathrm{m}^{-2}$ for blockfields resulting in overestimation. This was compensated by introducing $0.0 \mathrm{~kg} \mathrm{C} \mathrm{m}^{-2}$ SOC pseudo-training examples. At the same time, the SOCTot may be underestimated in small parts of the mires as the applied RF model cannot predict values beyond the range of the input data, e.g., in case the peat accumulation exceeds the maximum thickness of $138 \mathrm{~cm}$ that was sampled. Also, potential shifts in environmental gradients that have not been sampled, i.e., changes in geology, may have strong influence on SOC storage. These demands on pedon databases are analogous to the ones outlined by Hugelius (2012) for making credible thematic maps.

Further, sources of uncertainty include the strong dependence of the RF model to the LCC that could result from overfitting. Yet, the error metrics derived from crossvalidation indicate reliable results. A single dominating predictor variable has also been reported by other authors (e.g., Hengl et al., 2015). The fast degradation of permafrost in the environment has likely led to temporal differences in the high-resolution predictive datasets. For instance, areas visible as peat bog in the orthophoto from 2008 have since been submerged by water due to permafrost degradation, result- ing in a mismatch with soil pedons collected in 2013-2015. Error propagation from the generation of the LCC and the use of the LCC as input variable and for stratified extraction cannot be ruled out. Different spatial resolutions of the input data can reduce the spatial accuracy of higher resolution input layers. Future applications of machine-learning methods in this context should investigate spatial resolution optimization of input variables (Behrens et al., 2010; Drăguţ et al., 2009) and quantitative uncertainty estimates with confidence intervals for the predicted SOC distribution (Hugelius, 2012; Hugelius et al., 2014; Zhu, 2000).

\subsection{Environmental controls of SOC distribution}

A set of environmental variables with varying quality and spatial resolutions was used for the prediction of SOC-Tot at $1 \mathrm{~m}$ resolution. Land cover is the most important variable, followed by TWI, a group of input variables based on the SPOT5 image, including NIR, NIR/SWIR and NDVI, and elevation. The relevance of land cover for the prediction model likely reflects its ability to segment distinct soil bodies and sharp transitions between land covers at high resolution. This seems to be particularly important to map high SOC stocks related to deep OL depths and peat deposits, as the importance of the LCC is diminished for the estimate of SOC $0-30$ and SOC 0-100 (Fig. S1). Furthermore, the LCC is an integrated parameter combining information from several data sources. The vegetation sensitive SPOT5 bands and derived indices complement the LCC with information on vegetation productivity and the fraction of bare ground cover (Andersson, 2016; Huete, 1988; Rouse et al., 1974). The contribution of the TWI data is to identify soil moisture gradients. This is supported by curvature and is particularly evident for alpine willow communities that are located along flow accumulation pathways. Elevation likely reflects vegetation productivity as a function of the lapse rate of the mean annual air temperature gradient in steep mountainous terrain. Five other variables were excluded due to multicollinearity. The importance of NDVI in combination with TWI to predict SOC has also been reported by Taghizadeh-Mehrjardi et al. (2016).

It is known that the scale of an environmental variable can have significant influence on the prediction accuracy and the highest resolution is not always providing the highest accuracy (Behrens et al., 2005; Drăguţ et al., 2009). Despite the highest spatial resolution of $1 \mathrm{~m}$, the red band of the orthophoto was only the 6th most important prediction variable. While the LCC was constructed at $1 \mathrm{~m}$ resolution, each patch has a minimum size of $130 \mathrm{~m}^{2}$, which is similar to the pixel size of the SPOT5 variables at $10-20 \mathrm{~m}$ resolution. The DEM has an original resolution of $2 \mathrm{~m}$ and its derivative TWI is the second most important variable. While there is no clear trend for the variable importance, the visual inspection shows that lower resolution environmental variables create pixel artifacts. An exclusion of all SPOT5 input variables was tested, but significantly reduced model performance (re- 
sult not shown). This indicates that even lower resolution environmental variables can improve the final prediction if they support higher resolution datasets. However, Samuel-Rosa et al. (2015) found that more detailed environmental variables only improved model performance incrementally and the cost may outweigh the benefits. Instead, efforts should be placed in more soil pedon data, which should also be a priority in permafrost environments.

\subsection{Comparing the present-day SOC storage}

This study provides the first landscape-scale estimate and partitioning of SOC for the Abisko region. A mean landscape storage of $8.3 \pm 8.0 \mathrm{~kg} \mathrm{C} \mathrm{m}^{-2}$ for the SOC-Tot and $7.7 \pm 6.2 \mathrm{~kg} \mathrm{C} \mathrm{m}^{-2}$ for the SOC $0-100$ is predicted. Overall, the predicted estimates are in line with previous studies for individual land cover types. In the mires of the study area, Klaminder et al. (2008) found organic matter stocks of $30-80 \mathrm{~kg} \mathrm{~m}^{-2}$ on hummocks (peat bogs) and $35-110 \mathrm{~kg} \mathrm{~m}^{-2}$ in hollows (wetlands), which translates into similar amounts of SOC as estimated in this study. Some publications have emphasized higher amounts of SOC in tundra heath $\sim 7-$ $9 \mathrm{~kg} \mathrm{C} \mathrm{m}^{-2}$ compared to birch forest $\sim 4-5 \mathrm{~kg} \mathrm{C} \mathrm{m}^{-2}$ (Hartley et al., 2012; Parker et al., 2015). The sampled and predicted values for these classes are in the same range in this study, but higher amounts of SOC in tundra heath cannot be confirmed.

Few studies have estimated landscape SOC stocks in mountainous environments in permafrost regions. Low storage of SOC was documented by Fuchs et al. (2015) in a sub-Arctic alpine valley $50 \mathrm{~km}$ south of Stordalen. The SOC stocks vary from 0.05 to $8.4 \mathrm{~kg} \mathrm{C} \mathrm{m}^{-2}$ for different land cover classes, with a landscape mean SOC storage of $0.9 \pm 0.2 \mathrm{~kg} \mathrm{C} \mathrm{m}^{-2}$. Dörfer et al. (2013) estimate SOC stocks for two study areas on the Tibetan Plateau to 3.4 and $10.4 \mathrm{~kg} \mathrm{C} \mathrm{m}^{-2}$ for the top $0-30 \mathrm{~cm}$ of soil. For the Abisko area, a value of $3.9 \pm 1.8 \mathrm{~kg} \mathrm{C} \mathrm{m}^{-2}$ is calculated for the same depth interval showing a good agreement. A study with a similar environmental setting is presented by Palmtag et al. (2015) for Zackenberg, NE Greenland. This landscape features a combination of higher located barren alpine areas and lower located wetland areas including palsas. They found a mean landscape SOC storage of $8.3 \pm 1.8 \mathrm{~kg} \mathrm{C} \mathrm{m}^{-2}$ for the top meter. This compares well to this study, despite the location in the High Arctic. This could be explained by decreased decomposition rates and slower $\mathrm{C}$ turnover in Greenland (Hobbie et al., 2000).

\subsection{From local to circumpolar scale}

The estimated $7.7 \pm 6.2 \mathrm{~kg} \mathrm{C} \mathrm{m}^{-2}$ for the SOC $0-100$ in Abisko is considerably lower than the $26.1 \mathrm{~kg} \mathrm{C} \mathrm{m}^{-2}$ estimated for the same area at a circumpolar scale in the NCSCD (Hugelius et al., 2013, 2014). A similar discrepancy has been noted for example by Fuchs et al. (2015) and Palmtag et al. (2016) for study areas in Sweden and Siberia. The NCSCD is based on thematic mapping using soil polygons for northern Europe with an average area of $205 \pm 890 \mathrm{~km}^{2}$ and averages many soil pedons for individual soil types across the entire Arctic. The Abisko study area falls in a single polygon in the NCSCD. Clearly, the large generalization and the thematic mapping approach cannot reflect local-scale soil properties in this and other highly diverse permafrost environments.

Using digital soil mapping in combination with machinelearning methods can in the future provide improved, pixelbased regional to circumpolar estimates of SOC. The spatial resolution of such products is largely restricted by the available spatial input data and by computing resources. The spatial prediction approach provides stable results at resolutions of 2, 10 and $30 \mathrm{~m}$ for the SOC-Tot and for the SOC estimated under different land cover classes (Fig. 8). A significant drop in quality of the estimate occurs between a resolution of 30 and $100 \mathrm{~m}$. This results in an underestimation of the SOC-Tot at resolutions of 100, 250 and $1000 \mathrm{~m}$, as wetland classes can no longer be resolved by the spatial predictor variables. This is associated with a drop in $R^{2}$ from $\sim 0.7$ at resolutions $<30 \mathrm{~m}$ to $\sim 0.5$ at resolutions $>30 \mathrm{~m}$. This confirms results found by Hugelius (2012) using a similar approach with thematic maps. The importance of wetlands for SOC global stocks has long been pointed out. While they store large amounts of SOC, they typically occupy only a small fraction of the landscape (Gorham, 1991). In Abisko, wetlands store $25 \%$ of the carbon, but cover only $6 \%$ of the area (Fig. 7). Major wetland complexes can be mapped at coarse resolution, but small ones are often omitted and high-resolution approaches are necessary to extract this information (Hugelius, 2012; Virtanen and Ek, 2014). For example, Hugelius et al. (2011) showed for a study area in the European Russian Arctic, that a Quickbird-based $2.4 \mathrm{~m}$ spatial resolution LCC was necessary to map peat plateaus that store $30-58 \%$ of the ecosystem C dominated by SOC, while covering less than $\sim 20 \%$ of the area. Subsetting the SOCTot map for Abisko to show only wetland classes highlights the fragmentation and dispersion of minor wetlands detached from major wetland complexes (Fig. S2h). The significance of these smaller wetlands for $\mathrm{C}$ cycling at a landscape scale has so far found little attention in the literature.

Future updates at a circumpolar scale would clearly benefit from including high-resolution data derived from Sentinel$2(10 \mathrm{~m})$ and Landsat $(30 \mathrm{~m})$ satellites or the ArcticDEM (2017; 2-5 m). At such resolutions, SOC estimates may be considered reliable in environments similar to Abisko. However, areas with a significant amount of ice-wedge polygons may require higher-resolution mapping approaches (Siewert et al., 2015, 2016). At the same time, this will need considerable amounts of computing power. Estimates using data from satellites like MODIS (250-1000 m) and AVHRR (1100 m) are likely to underestimate SOC stocks and may not reflect extreme values. At regional to circumpolar scales, it will also 
be necessary to include climatic datasets as environmental variables to correctly model the SOC storage. For example, Klaminder et al. (2009) find a clear connection between mean annual precipitation and SOC stored in tundra soils along a transect from Abisko towards the more humid western coast (not covered here). Future research should also investigate the use of new predictive variables, such as synthetic aperture radar remote sensing data. This product is sensitive to soil moisture and has recently been used to continuously map SOC at a circumpolar scale north of the tree line (Bartsch et al., 2016). A priority should, however, be the collection of soil pedons. The latest circumpolar SOC estimate for the top meter is based on only 1778 pedons and reports substantial regional gaps in pedon data. This is particularly the case for areas in the High Arctic with thin sediment overburden for cryoturbated soils and for peatland soils (Hugelius et al., 2014). Similarly, it was shown for the SOC storage in Alaska, that despite 556 existing soil pedons, $>300$ additional soil pedons are necessary to reflect the entire environmental space (Vitharana et al., 2017).

\subsection{SOC age - past and future development}

A major research question is whether Arctic environments have in the past been a sink or a source of $\mathrm{C}$ and how this will develop in the future. The Abisko region was deglaciated around 9500 cal BP (Berglund et al., 1996), leaving a glacier-forefield-like landscape with no SOC. This study finds that initial peat inception in Stordalen took place around 5200 years ago in the central part of the mire, while other studies indicate peat inception between 6000 and 4700 years for different parts of the mire (Sonesson, 1972; Kokfelt et al., 2010). Other profiles from different parts of the mire indicate an initial peat deposition and a transition to pure peat between 1900 and $2200 \mathrm{cal} \mathrm{BP}$. This peat has likely accumulated due to peat erosion from already developed peat deposits in the surrounding, followed by continuous peat production. Similarly, Kokfelt et al. (2010) found a change towards ombrotrophic conditions and potential permafrost aggradation taking place around $2800 \mathrm{cal} \mathrm{BP}$ and prevailing permafrost conditions between 2650-2100 cal BP. This was followed by a phase of thermokarst and peat erosion and SOC accumulation in surrounding lakes. After $700 \mathrm{cal}$ BP permafrost conditions reappeared and palsa formation took place in the northern part of the mire around $120 \mathrm{calBP}$ (Kokfelt et al., 2010). This interpretation with relatively stable accumulation of SOC in the past 2000 is coherent with the results in this article.

The majority of the sampled SOC in the birch forest has an age of less than 1350 years. No signs of significant SOC burial due to solifluction or cryoturbation processes were found. However, these processes can store significant amounts of SOC in alpine and tundra terrain (Palmtag et al., 2015; Siewert et al., 2016) and are a common phenomenon on some slopes of the area. Becher et al. (2013) found three major periods of burial of SOC in non-sorted circles near Abisko, that coincide with transitions from colder to warmer conditions dated to 0-100, 900-1250 and 1650-1950 AD.

In summary, the bulk of the present-day SOC in the study area must have accumulated during the past 2000 years. Despite some episodes of palsa and peat plateau degradation and peat erosion, it can be assumed that the study area has over the time period of the Holocene been a $\mathrm{C}$ sink, with a significant portion of the SOC stored in labile and temperature-sensitive peat plateaus.

At present, permafrost of the peat plateaus of northern Fennoscandia seems to be at a critical thermal limit and close to collapse. In the Abisko region, permafrost is warming rapidly (Johansson et al., 2011). In Stordalen, a decrease in dry peat plateau areas by $10 \%$ and an increase in wet graminoid-dominated water areas by $17 \%$ has been documented for the period from 1970 to 2000 and was likely caused by permafrost degradation (Malmer et al., 2005). In Tavvavuoma, a peat plateau/thermokarst lake complex located in the sporadic permafrost zone in northern Sweden, the same trend is observed. Here significant thermokarst lake formation, drainage and infilling with fen vegetation has occurred from 1963 to 2003 (Sannel and Kuhry, 2011). These are significant landscape changes that affect the $\mathrm{C}$ balance in peat plateau areas and the permafrost in this area is clearly not in equilibrium with the present-day warmer climate causing dynamic adjustments.

How these adjustments will influence the carbon balance in the future seems unclear. Lundin et al. (2016) find that the Stordalen catchment is unlikely to be a present-day C sink, but rather acts as a source of C. However, Fuchs et al. (2015) argue for the alpine Tarfala valley with very low SOC stocks, that these landscapes will under future climatic changes turn into a sink of $\mathrm{C}$, despite degradation of the permafrost, as biomass will increase and soils develop. In Abisko most of the SOC is stored in birch forest soils. A further shrubification of alpine areas and a rise of the tree line combined with a positive priming effect could bind more SOC in the aboveground vegetation (Hartley et al., 2012). Yet, for most permafrost environments this is unlikely to offset SOC releases from the permafrost and deeper soil layers by mass (Siewert et al., 2015) and may even lead to a release of SOC (Hartley et al., 2012). In wetlands, an increase in sedge and Eriophorum-dominated water-submerged areas will be important to regulate dissolved organic carbon and SOC dynamics (Tang et al., 2018). Furthermore, the role of many minor wetland areas revealed by high-resolution mapping has not received sufficient attention. Indeed, a holistic perspective will be necessary to predict how SOC storages will evolve in post-permafrost landscapes in the future. 


\section{Conclusions}

Few studies have applied digital soil mapping techniques to map soil organic carbon (SOC) in sub-Arctic and Arctic permafrost environments. In general, thematic mapping approaches have been favored. Promising results have been obtained using machine-learning techniques to predict SOC in a mountainous sub-Arctic peatland environment with typical periglacial landforms such as permafrost raised peat plateaus. A random forest prediction model showed the best results in terms of error metrics and upon visual inspection. Digital soil mapping of SOC is a significant improvement over upscaling methods using thematic maps such as land cover classifications (LCCs). Yet, carefully generated thematic maps remain essential to our understanding of a landscape, its partitioning and patchiness. Thematic maps can be used as a predictor variable and for stratified extraction of soil properties such as SOC. This will help to understand these variables at the landscape level.

For the Abisko study area, the mean landscape total SOC storage is estimated to be $8.3 \pm 8.0 \mathrm{~kg} \mathrm{C} \mathrm{m}^{-2}$ and the 0 $100 \mathrm{~cm}$ storage to be $7.7 \pm 6.2 \mathrm{~kg} \mathrm{Cm}^{-2}$ at a spatial resolution of $1 \mathrm{~m}$. This estimate is significantly lower than the estimates from the Northern Circumpolar Soil Carbon Database, but in line with other high-resolution mapping results of SOC storage in similar environments, indicating the value of highresolution upscaling and partitioning studies. Reducing the spatial resolution of the environmental input data reveals a significant drop in mapping accuracy for resolutions coarser than $30 \mathrm{~m}$, and a tendency to underestimate SOC stocks. The amount of soil pedon data is clearly the limiting factor to map SOC in permafrost environments. Future field surveys must pay attention to sample the entire environmental gradient, including low $\mathrm{C}$ storage end-members. This applies to local as well as circumpolar scales, where large regional soil pedon gaps remain especially for areas with low SOC stocks. Many small wetlands are not mapped at coarse resolutions and the results highlight the importance of peatlands and peat plateaus for the total SOC stocks in sub-Arctic environments. Most SOC in the study area was accumulated during the past 2000 years. The landscape history emphasises that presentday SOC stocks represent a snapshot in time in an ecosystem that is subject to continuous environmental adaptation associated with permafrost degradation caused by climate change. A holistic approach will be necessary to understand how permafrost degradation will affect the landscape distribution of SOC in the future.

Data availability. The following data is archived on the PANGAEA database:

- Soil pedon data: https://doi.org/10.1594/PANGAEA.887418 (Siewert, 2018a)

- Land cover classification: https://doi.org/10.1594/PANGA EA.886298 (Siewert, 2018b)
- Maps of soil organic carbon and organic layer depth: https://doi.org/10.1594/PANGAEA.886296 (Siewert, 2018c)

Access to the individual environmental predictor variables is described on https://www.geodata.se/.

\section{The Supplement related to this article is available online at https://doi.org/10.5194/bg-15-1663-2018-supplement.}

Competing interests. The author declares that he has no conflict of interest.

Special issue statement. This article is part of the special issue "Changing Permafrost in the Arctic and its Global Effects in the 21st Century (PAGE21) (BG/ESSD/GMD/TC inter-journal SI)". It is not associated with a conference.

Acknowledgements. The soil data used in this study was collected as part of the European Union FP7 - ENVIRONMENT project PAGE21 (grant number 282700), the NordForsk DEFROST (grant number 23001) project and with the support of the Bolin Centre for Climate Research (grant to Juri Palmtag). I would like to thank Matthias Fuchs, Jannike Andersson, Juri Palmtag and Robin Wojcik for their assistance during fieldwork. I also thank Matthias Fuchs and Robin Wojcik for the analysis of the soil samples. I thank Peter Kuhry for his valuable advice on my work. I greatly acknowledge Gustaf Hugelius for his insightful comments on the manuscript and his continuous support.

Edited by: Susan Natali

Reviewed by: four anonymous referees

\section{References}

Åkerman, H. J. and Johansson, M.: Thawing permafrost and thicker active layers in sub-arctic Sweden, Permafrost Periglac., 19, 279-292, https://doi.org/10.1002/ppp.626, 2008.

Andersson, J.: Assessing the ecosystem carbon storage in two subarctic areas - Phytomass and soil organic carbon stock at Abisko in Sweden and Utsjoki in Finland, Master Thesis, 22 January 2016, Stockholm University, Stockholm, 2016.

ArcticDEM: ArcticDEM, available at: https://www.pgc.umn.edu/ data/arcticdem/ (last access: 12 March 2018), 2017.

Bartsch, A., Widhalm, B., Kuhry, P., Hugelius, G., Palmtag, J., and Siewert, M. B.: Can C-band synthetic aperture radar be used to estimate soil organic carbon storage in tundra?, Biogeosciences, 13, 5453-5470, https://doi.org/10.5194/bg-13-5453-2016, 2016.

Baughman, C. A., Mann, D. H., Verbyla, D. L., and Kunz, M. L.: Soil surface organic layers in Arctic Alaska: Spatial distribution, rates of formation, and microclimatic effects, J. Geophys. Res.-Biogeo., 120, 1150-1164, https://doi.org/10.1002/2015JG002983, 2015. 
Becher, M., Olid, C., and Klaminder, J.: Buried soil organic inclusions in non-sorted circles fields in northern Sweden: Age and Paleoclimatic context, J. Geophys. Res.-Biogeo., 118, 104-111, https://doi.org/10.1002/jgrg.20016, 2013.

Behrens, T., Förster, H., Scholten, T., Steinrücken, U., Spies, E.-D., and Goldschmitt, M.: Digital soil mapping using artificial neural networks, J. Plant Nutr. Soil Sc., 168, 21-33, https://doi.org/10.1002/jpln.200421414, 2005.

Behrens, T., Zhu, A.-X., Schmidt, K., and Scholten, T.: Multi-scale digital terrain analysis and feature selection for digital soil mapping, Geoderma, 155, 175-185, https://doi.org/10.1016/j.geoderma.2009.07.010, 2010.

Berglund, B. E., Barnekow, L., Hammarlund, D., Sandgren, P., and Snowball, I. F.: Holocene forest dynamics and climate changes in the Abisko area, northern Sweden: the Sonesson model of vegetation history reconsidered and confirmed, Ecol. Bull., 45, 15-30, 1996.

Blaschke, T.: Object based image analysis for remote sensing, ISPRS J. Photogramm. Remote Sens., 65(1), 2-16, https://doi.org/10.1016/j.isprsjprs.2009.06.004, 2010.

Boettinger, J. L., Howell, D. W., Moore, A. C., Hartemink, A. E., and Kienast-Brown, S. (Eds.): Digital Soil Mapping, Springer Netherlands, Dordrecht, https://doi.org/10.1007/97890-481-8863-5, 2010.

Breiman, L.: Random forests, Mach. Learn., 45, 5-32, 2001.

Bronk Ramsey, C.: OxCal 4.2, available at: https://c14.arch.ox. ac.uk/embed.php?File=oxcal.html (last access: 28 April 2016), 2016.

Brown, J., Ferrians, O. J., Heginbottom, J. A., and Melnikov, E. S.: Circum-Arctic map of permafrost and ground-ice conditions, National Snow and Ice Data Center, Boulder, Colorado, available at: http://pubs.usgs.gov/cp/45/report.pdf (last access: 6 June 2013), 1997.

Callaghan, T. V., Jonasson, C., Thierfelder, T., Yang, Z., Hedenas, H., Johansson, M., Molau, U., Van Bogaert, R., Michelsen, A., Olofsson, J., Gwynn-Jones, D., Bokhorst, S., Phoenix, G., Bjerke, J. W., Tommervik, H., Christensen, T. R., Hanna, E., Koller, E. K., and Sloan, V. L.: Ecosystem change and stability over multiple decades in the Swedish subarctic: complex processes and multiple drivers, Philos. T. Roy. Soc. B, 368, 20120488, https://doi.org/10.1098/rstb.2012.0488, 2013.

Chang, C.-C. and Lin, C.-J.: LIBSVM: A library for support vector machines, ACM Trans. Intel. Syst. Tec., 2, 27, https://doi.org/10.1145/1961189.1961199, 2011.

Christensen, T. R., Johansson, T., Åkerman, H. J., Mastepanov, M., Malmer, N., Friborg, T., Crill, P., and Svensson, B. H.: Thawing sub-arctic permafrost: Effects on vegetation and methane emissions, Geophys. Res. Lett., 31, L04501, https://doi.org/10.1029/2003GL018680, 2004.

Congalton, R. G.: A review of assessing the accuracy of classifications of remotely sensed data, Remote Sens. Environ., 37, 35-46, https://doi.org/10.1016/0034-4257(91)90048-B, 1991.

Conrad, O., Bechtel, B., Bock, M., Dietrich, H., Fischer, E., Gerlitz, L., Wehberg, J., Wichmann, V., and Böhner, J.: System for Automated Geoscientific Analyses (SAGA) v. 2.1.4, Geosci. Model Dev., 8, 1991-2007, https://doi.org/10.5194/gmd-8-1991-2015, 2015.
Davidson, E. A. and Janssens, I. A.: Temperature sensitivity of soil carbon decomposition and feedbacks to climate change, Nature, 440, 165-173, 2006.

Ding, J., Li, F., Yang, G., Chen, L., Zhang, B., Liu, L., Fang, K., Qin, S., Chen, Y., Peng, Y., Ji, C., He, H., Smith, P., and Yang, Y.: The permafrost carbon inventory on the Tibetan Plateau: a new evaluation using deep sediment cores, Glob. Change Biol., 22, 2688-2701, https://doi.org/10.1111/gcb.13257, 2016.

Dörfer, C., Kühn, P., Baumann, F., He, J.-S., and Scholten, T.: Soil Organic Carbon Pools and Stocks in Permafrost-Affected Soils on the Tibetan Plateau, edited by: Slomp, C. P., PLoS ONE, 8, e57024, https://doi.org/10.1371/journal.pone.0057024, 2013.

Drăguţ, L., Schauppenlehner, T., Muhar, A., Strobl, J., and Blaschke, T.: Optimization of scale and parametrization for terrain segmentation: An application to soillandscape modeling, Comput. Geosci., 35, 1875-1883, https://doi.org/10.1016/j.cageo.2008.10.008, 2009.

FAO: World reference base for soil resources 2014 international soil classification system for naming soils and creating legends for soil maps Update 2015, FAO, Rome, 2015.

Forkuor, G., Hounkpatin, O. K. L., Welp, G., and Thiel, M.: High Resolution Mapping of Soil Properties Using Remote Sensing Variables in South-Western Burkina Faso: A Comparison of Machine Learning and Multiple Linear Regression Models, PLoS ONE, 12, e0170478, https://doi.org/10.1371/journal.pone.0170478, 2017.

Fuchs, M., Kuhry, P., and Hugelius, G.: Low below-ground organic carbon storage in a subarctic Alpine permafrost environment, The Cryosphere, 9, 427-438, https://doi.org/10.5194/tc-9-4272015, 2015.

GDAL: GDAL - Geospatial Data Abstraction Library: Version 1.11.2, Open Source Geospatial Foundation, 2016.

Gorham, E.: Northern Peatlands: Role in the Carbon Cycle and Probable Responses to Climatic Warming, Ecol. Appl., 1, 182195, https://doi.org/10.2307/1941811, 1991.

Guisan, A., Weiss, S. B., and Weiss, A. D.: GLM versus CCA spatial modeling of plant species distribution, Plant Ecol., 143, 107122, 1999.

Hartley, I. P., Garnett, M. H., Sommerkorn, M., Hopkins, D. W., Fletcher, B. J., Sloan, V. L., Phoenix, G. K., and Wookey, P. A.: A potential loss of carbon associated with greater plant growth in the European Arctic, Nat. Clim. Change, 2, 875-879, https://doi.org/10.1038/nclimate1575, 2012.

Hastie, T., Tibshirani, R., and Friedman, J.: The Elements of Statistical Learning, Springer New York, New York, NY, https://doi.org/10.1007/978-0-387-84858-7, 2009.

Heiri, O., Lotter, A. F., and Lemcke, G.: Loss on ignition as a method for estimating organic and carbonate content in sediments: reproducibility and comparability of results, J. Paleolimnol., 25, 101-110, https://doi.org/10.1023/A:1008119611481, 2001.

Hengl, T., Heuvelink, G. B. M., Kempen, B., Leenaars, J. G. B., Walsh, M. G., Shepherd, K. D., Sila, A., MacMillan, R. A., Jesus, J. M. de, Tamene, L., and Tondoh, J. E.: Mapping Soil Properties of Africa at $250 \mathrm{~m}$ Resolution: Random Forests Significantly Improve Current Predictions, PLOS ONE, 10, e0125814, https://doi.org/10.1371/journal.pone.0125814, 2015. 
Hobbie, S. E., Schimel, J. P., Trumbore, S. E., and Randerson, J. R.: Controls over carbon storage and turnover in high-latitude soils, Glob. Change Biol., 6, 196-210, 2000.

Huete, A. R.: A soil-adjusted vegetation index (SAVI), Remote Sens. Environ., 25, 295-309, https://doi.org/10.1016/00344257(88)90106-X, 1988.

Hugelius, G.: Spatial upscaling using thematic maps: An analysis of uncertainties in permafrost soil carbon estimates, Global Biogeochem. Cy., 26, GB2026, https://doi.org/10.1029/2011GB004154, 2012.

Hugelius, G. and Kuhry, P.: Landscape partitioning and environmental gradient analyses of soil organic carbon in a permafrost environment, Global Biogeochem. Cy., 23, GB3006, https://doi.org/10.1029/2008GB003419, 2009.

Hugelius, G., Kuhry, P., Tarnocai, C., and Virtanen, T.: Soil organic carbon pools in a periglacial landscape: a case study from the central Canadian Arctic, Permafrost Periglac., 21, 16-29, https://doi.org/10.1002/ppp.677, 2010.

Hugelius, G., Virtanen, T., Kaverin, D., Pastukhov, A., Rivkin, F., Marchenko, S., Romanovsky, V., and Kuhry, P.: Highresolution mapping of ecosystem carbon storage and potential effects of permafrost thaw in periglacial terrain, European Russian Arctic, J. Geophys. Res., 116, G03024, https://doi.org/10.1029/2010JG001606, 2011.

Hugelius, G., Tarnocai, C., Broll, G., Canadell, J. G., Kuhry, P., and Swanson, D. K.: The Northern Circumpolar Soil Carbon Database: spatially distributed datasets of soil coverage and soil carbon storage in the northern permafrost regions, Earth Syst. Sci. Data, 5, 3-13, https://doi.org/10.5194/essd-5-3-2013, 2013.

Hugelius, G., Strauss, J., Zubrzycki, S., Harden, J. W., Schuur, E. A. G., Ping, C.-L., Schirrmeister, L., Grosse, G., Michaelson, G. J., Koven, C. D., O’Donnell, J. A., Elberling, B., Mishra, U., Camill, P., Yu, Z., Palmtag, J., and Kuhry, P.: Estimated stocks of circumpolar permafrost carbon with quantified uncertainty ranges and identified data gaps, Biogeosciences, 11, 6573-6593, https://doi.org/10.5194/bg-11-6573-2014, 2014.

IPCC: Climate change 2013: The physical science basis, edited by: Stocker, T. F., Qin, D., Plattner, G.-K., Tignor, M., Allen, S. K., Boschung, J., Nauels, A., Xia, Y., Bex, V., and Midgley, P. M., Intergov. Panel Clim. Change Work. Group Contrib. IPCC Fifth Assess. Rep. AR5Cambridge Univ Press N.Y., available at: http://www.climatechange2013.org/images/report/ WG1AR5_Frontmatter_FINAL.pdf (last access: 26 November 2014), 2013.

Johansson, M., Akerman, J., Keuper, F., Christensen, T. R., Lantuit, H., and Callaghan, T. V.: Past and Present Permafrost Temperatures in the Abisko Area: Redrilling of Boreholes, Ambio, 40, 558-565, https://doi.org/10.1007/s13280-011-0163-3, 2011.

Jonasson, C., Sonesson, M., Christensen, T. R., and Callaghan, T. V.: Environmental Monitoring and Research in the Abisko Area - An Overview, Ambio, 41, 178-186, https://doi.org/10.1007/s13280-012-0301-6, 2012.

Klaminder, J., Yoo, K., Rydberg, J., and Giesler, R.: An explorative study of mercury export from a thawing palsa mire, J. Geophys. Res.-Biogeo., 113, G04034, https://doi.org/10.1029/2008JG000776, 2008.

Klaminder, J., Yoo, K., and Giesler, R.: Soil carbon accumulation in the dry tundra: Important role played by precipitation, J. Geophys. Res.-Biogeo., 114, G04005, https://doi.org/10.1029/2009JG000947, 2009.

Köchy, M., Hiederer, R., and Freibauer, A.: Global distribution of soil organic carbon - Part 1: Masses and frequency distributions of SOC stocks for the tropics, permafrost regions, wetlands, and the world, SOIL, 1, 351-365, https://doi.org/10.5194/soil-1-3512015, 2015.

Kokfelt, U., Reuss, N., Struyf, E., Sonesson, M., Rundgren, M., Skog, G., Rosén, P., and Hammarlund, D.: Wetland development, permafrost history and nutrient cycling inferred from late Holocene peat and lake sediment records in subarctic Sweden, J Paleolimnol., 44, 327-342, https://doi.org/10.1007/s10933-0109406-8, 2010.

Kuhn, M.: Building Predictive Models in R Using the caret Package, J. Stat. Softw., 28, 1-26, https://doi.org/10.18637/jss.v028.i05, 2008a.

Kuhn, M.: Caret package, J. Stat. Softw., 28, 1-26, 2008 b.

Law, K. H. and Nichol, J.: Topographic correction for differential illumination effects on IKONOS satellite imagery, Int. Arch. Photogramm. Remote Sens. Spat. Inf. Sci., 35, 641-646, 2004.

Li, J. and Heap, A.: A review of spatial interpolation methods for environmental scientists, Geoscience Australia, Canberra, 2008.

Li, J., Heap, A. D., Potter, A., and Daniell, J. J.: Application of machine learning methods to spatial interpolation of environmental variables, Environ. Modell. Softw., 26, 1647-1659, https://doi.org/10.1016/j.envsoft.2011.07.004, 2011.

Liaw, A. and Wiener, M.: Classification and regression by randomForest, R News, 2, 18-22, 2002.

Lin, L. I.-K.: A Concordance Correlation Coefficient to Evaluate Reproducibility, Biometrics, 45, 255-268, https://doi.org/10.2307/2532051, 1989.

Lundin, E. J., Klaminder, J., Giesler, R., Persson, A., Olefeldt, D., Heliasz, M., Christensen, T. R., and Karlsson, J.: Is the subarctic landscape still a carbon sink? Evidence from a detailed catchment balance, Geophys. Res. Lett., 43, 1988-1995, https://doi.org/10.1002/2015GL066970, 2016.

Malmer, N., Johansson, T., Olsrud, M., and Christensen, T. R.: Vegetation, climatic changes and net carbon sequestration in a North-Scandinavian subarctic mire over 30 years, Glob. Change Biol., 11, 1895-1909, https://doi.org/10.1111/j.13652486.2005.01042.x, 2005.

McBratney, A. B., Mendonça Santos, M. L., and Minasny, B.: On digital soil mapping, Geoderma, 117, 3-52, https://doi.org/10.1016/S0016-7061(03)00223-4, 2003.

McGuire, A. D., Anderson, L. G., Christensen, T. R., Dallimore, S., Guo, L., Hayes, D. J., Heimann, M., Lorenson, T. D., Macdonald, R. W., and Roulet, N.: Sensitivity of the carbon cycle in the Arctic to climate change, Ecol. Monogr., 79, 523-555, 2009.

Mishra, U. and Riley, W. J.: Alaskan soil carbon stocks: spatial variability and dependence on environmental factors, Biogeosciences, 9, 3637-3645, https://doi.org/10.5194/bg-9-36372012, 2012.

Mishra, U. and Riley, W. J.: Active-Layer Thickness across Alaska: Comparing Observation-Based Estimates with CMIP5 Earth System Model Predictions, Soil Sci. Soc. Am. J., 78, 894-902, https://doi.org/10.2136/sssaj2013.11.0484, 2014.

Mishra, U., Jastrow, J. D., Matamala, R., Hugelius, G., Koven, C. D., Harden, J. W., Ping, C. L., Michaelson, G. J., Fan, Z., Miller, R. M., McGuire, A. D., Tarnocai, C., Kuhry, P., Riley, W. J., 
Schaefer, K., Schuur, E. A. G., Jorgenson, M. T., and Hinzman, L. D.: Empirical estimates to reduce modeling uncertainties of soil organic carbon in permafrost regions: a review of recent progress and remaining challenges, Environ. Res. Lett., 8, 035020, https://doi.org/10.1088/1748-9326/8/3/035020, 2013.

Moore, I. D., Grayson, R. B., and Ladson, A. R.: Digital terrain modelling: a review of hydrological, geomorphological, and biological applications, Hydrol. Process., 5, 3-30, 1991.

Palmtag, J., Hugelius, G., Lashchinskiy, N., Tamtorf, M. P., Richter, A., Elberling, B., and Kuhry, P.: Storage, landscape distribution, and burial history of soil organic matter in contrasting areas of continuous permafrost, Arct. Antarct. Alp. Res., 47, 71-88, https://doi.org/10.1657/AAAR0014-027, 2015.

Palmtag, J., Ramage, J., Hugelius, G., Gentsch, N., Lashchinskiy, N., Richter, A., and Kuhry, P.: Controls on the storage of organic carbon in permafrost soil in northern Siberia: Soil organic carbon storage in permafrost terrain, northern Siberia, Eur. J. Soil Sci., 67, 478-491, https://doi.org/10.1111/ejss.12357, 2016.

Parker, T. C., Subke, J.-A., and Wookey, P. A.: Rapid carbon turnover beneath shrub and tree vegetation is associated with low soil carbon stocks at a subarctic treeline, Glob. Change Biol., 21, 2070-2081, https://doi.org/10.1111/gcb.12793, 2015.

Pastick, N. J., Rigge, M., Wylie, B. K., Jorgenson, M. T., Rose, J. R., Johnson, K. D., and Ji, L.: Distribution and landscape controls of organic layer thickness and carbon within the Alaskan Yukon River Basin, Geoderma, 230, 79-94, 2014.

Ping, C.-L., Clark, M. H., Kimble, J. M., Michaelson, G. J., Shur, Y., and Stiles, C. A.: Sampling Protocols for Permafrost-Affected Soils, Soil Horiz., 54, 13-19, https://doi.org/10.2136/sh12-090027, 2013.

Ping, C. L., Jastrow, J. D., Jorgenson, M. T., Michaelson, G. J., and Shur, Y. L.: Permafrost soils and carbon cycling, SOIL, 1, 147171, https://doi.org/10.5194/soil-1-147-2015, 2015.

R Core Team: R: A language and environment for statistical computing, R Foundation for Statistical Computing, Vienna, Austria, available at: http://www.R-project.org (last access: 25 July 2014), 2017.

Ridefelt, H., Etzelmüller, B., Boelhouwers, J., and Jonasson, C.: Statistic-empirical modelling of mountain permafrost distribution in the Abisko region, sub-Arctic northern Sweden, Nor. Geogr. Tidsskr.-Nor. J. Geogr., 62, 278-289, https://doi.org/10.1080/00291950802517890, 2008

Ripley, B. D.: Pattern recognition and neural networks, Cambridge University press, available at: https://www.google.com/books? $\mathrm{hl}=\mathrm{sv} \& \mathrm{lr}=\& \mathrm{id}=\mathrm{m} 12 \mathrm{UR} 8 \mathrm{QmLqoC} \& \mathrm{oi}=$ fnd $\& \mathrm{pg}=\mathrm{PR} 9 \& \mathrm{dq}=$ Ripley+Pattern+Recognition+and+Neural+Networks+ Cambridge. \&ots $=$ aNNmeD-JXh\&sig=Xo5yVY294wsdwB_ 2Xkr7GtJehVU (last access: 29 April 2016), 1996.

Rouse, J. W., Haas, R. H., Schell, J. A., and Deering, D. W.: Monitoring vegetation systems in the Great Plains with ERTS, in Proceedings of the Third Earth Resources Technology Satellite-1 Symposium, 301-317, Nasa, Greenbelt, MD, available at: http: //adsabs.harvard.edu/abs/1974NASSP.351..309R (last access: 26 March 2016), 1974.

Samuel-Rosa, A., Heuvelink, G. B. M., Vasques, G. M., and Anjos, L. H. C.: Do more detailed environmental covariates deliver more accurate soil maps?, Geoderma, 243-244, 214-227, https://doi.org/10.1016/j.geoderma.2014.12.017, 2015.
Sannel, A. B. K. and Kuhry, P.: Warming-induced destabilization of peat plateau/thermokarst lake complexes, J. Geophys. Res.Biogeo., 116, G03035, https://doi.org/10.1029/2010JG001635, 2011.

Schneider, J., Grosse, G., and Wagner, D.: Land cover classification of tundra environments in the Arctic Lena Delta based on Landsat $7 \mathrm{ETM}+$ data and its application for upscaling of methane emissions, Remote Sens. Environ., 113, 380-391, https://doi.org/10.1016/j.rse.2008.10.013, 2009.

Schoeneberger, P. J., Wysocki, D. A., Benham, E. C., and Soil Survey Staff: Field book for describing and sampling soils, Version 3.0, Natural Resources Conservation Service, National Soil Survey Center, Lincoln, NE, 2012.

Schuur, E. A. G., McGuire, A. D., Schädel, C., Grosse, G., Harden, J. W., Hayes, D. J., Hugelius, G., Koven, C. D., Kuhry, P., Lawrence, D. M., Natali, S. M., Olefeldt, D., Romanovsky, V. E., Schaefer, K., Turetsky, M. R., Treat, C. C., and Vonk, J. E.: Climate change and the permafrost carbon feedback, Nature, 520, 171-179, https://doi.org/10.1038/nature14338, 2015.

Siewert, M. B.: Soil organic carbon storage and organic layer depth for the Stordalen catchment, Abisko, Sweden, https://doi.org/10.1594/PANGAEA.887418, 2018 a.

Siewert, M. B.: High-resolution land cover classification for Stordalen, Abisko region, northern Sweden, PANGAEA, https://doi.org/10.1594/PANGAEA.886298, 2018b.

Siewert, M. B.: High-resolution maps of soil organic carbon for Abisko, northern Sweden, PANGAEA, https://doi.org/10.1594/PANGAEA.886296, $2018 \mathrm{c}$.

Siewert, M. B., Krautblatter, M., Christiansen, H. H., and Eckerstorfer, M.: Arctic rockwall retreat rates estimated using laboratory-calibrated ERT measurements of talus cones in Longyeardalen, Svalbard, Earth Surf. Proc. Land., 37, 15421555, https://doi.org/10.1002/esp.3297, 2012.

Siewert, M. B., Hanisch, J., Weiss, N., Kuhry, P., Maximov, T. C., and Hugelius, G.: Comparing carbon storage of Siberian tundra and taiga permafrost ecosystems at very high spatial resolution: Ecosystem carbon in taiga and tundra, J. Geophys. Res.-Biogeo., 120, 1973-1994, https://doi.org/10.1002/2015JG002999, 2015.

Siewert, M. B., Hugelius, G., Heim, B., and Faucherre, S.: Landscape controls and vertical variability of soil organic carbon storage in permafrost-affected soils of the Lena River Delta, CATENA, 147, 725-741, https://doi.org/10.1016/j.catena.2016.07.048, 2016.

Sonesson, M.: Cryptogams, Int. Biol. Program. Tundra Biome Proj. Tech. Rep., Swedish Natural Science Research Council, Stockholm, 1972.

Taghizadeh-Mehrjardi, R., Nabiollahi, K., and Kerry, R.: Digital mapping of soil organic carbon at multiple depths using different data mining techniques in Baneh region, Iran, Geoderma, 266, 98-110, https://doi.org/10.1016/j.geoderma.2015.12.003, 2016.

Tang, J., Yurova, A. Y., Schurgers, G., Miller, P. A., Olin, S., Smith, B., Siewert, M. B., Olefeldt, D., Pilesjö, P., and Poska, A.: Drivers of dissolved organic carbon export in a subarctic catchment: Importance of microbial decomposition, sorptiondesorption, peatland and lateral flow, Sci. Total Environ., 622623, 260-274, https://doi.org/10.1016/j.scitotenv.2017.11.252, 2018.

Tarnocai, C., Canadell, J. G., Schuur, E. A. G., Kuhry, P., Mazhitova, G., and Zimov, S.: Soil organic carbon pools in the north- 
ern circumpolar permafrost region, Global Biogeochem. Cy., 23, GB2023, https://doi.org/10.1029/2008GB003327, 2009.

Vapnik, V. N.: Statistical learning theory, Springer, New York, 1998.

Virtanen, T. and Ek, M.: The fragmented nature of tundra landscape, Int. J. Appl. Earth Obs., 27, 4-12, https://doi.org/10.1016/j.jag.2013.05.010, 2014.

Virtanen, T., Mikkola, K., Nikula, A., Christensen, J. H., Mazhitova, G. G., Oberman, N. G., and Kuhry, P.: Modeling the location of the forest line in northeast European Russia with remotely sensed vegetation and GIS-based climate and terrain data, Arct. Antarct. Alp. Res., 36, 314-322, 2004.

Vitharana, U. W. A., Mishra, U., Jastrow, J. D., Matamala, R., and Fan, Z.: Observational needs for estimating Alaskan soil carbon stocks under current and future climate: Capturing Heterogeneity of Soil Carbon, J. Geophys. Res.-Biogeo., 122, 415-429, https://doi.org/10.1002/2016JG003421, 2017.

Were, K., Bui, D. T., Dick, O. B., and Singh, B. R.: A comparative assessment of support vector regression, artificial neural networks, and random forests for predicting and mapping soil organic carbon stocks across an Afromontane landscape, Ecol. Indic., 52, 394-403, https://doi.org/10.1016/j.ecolind.2014.12.028, 2015.
Wilson, M. F. J., O’Connell, B., Brown, C., Guinan, J. C., and Grehan, A. J.: Multiscale Terrain Analysis of Multibeam Bathymetry Data for Habitat Mapping on the Continental Slope, Mar. Geod., 30, 3-35, https://doi.org/10.1080/01490410701295962, 2007.

Zeileis, A., Hornik, K., Smola, A., and Karatzoglou, A.: kernlab-an S4 package for kernel methods in R, J. Stat. Softw., 11, 1-20, 2004.

Zhang, G. and Lu, Y.: Bias-corrected random forests in regression, J. Appl. Stat., 39, 151-160, https://doi.org/10.1080/02664763.2011.578621, 2012.

Zhu, A.-X.: Mapping soil landscape as spatial continua: The Neural Network Approach, Water Resour. Res., 36, 663-677, https://doi.org/10.1029/1999WR900315, 2000.

Zubrzycki, S., Kutzbach, L., Grosse, G., Desyatkin, A., and Pfeiffer, E.-M.: Organic carbon and total nitrogen stocks in soils of the Lena River Delta, Biogeosciences, 10, 3507-3524, https://doi.org/10.5194/bg-10-3507-2013, 2013. 